Türkiye Jeoloji Bülteni
Geological Bulletin of Turkey
$62(2019) 113-140$
doi: $10.25288 /$ tjb. 545084

\title{
Amerika, Orta Teksas'ta Yer Alan Edwards Akiferi'nde Karstik Yapıların ve Fay Karakterizasyonunun Bütünleşik Jeofizik Yöntemler Kullanılarak Araştırılması
}

Locating Karstic Features and Fault Characterization Using Integrated Geophysical Methods in the Edwards Aquifer, Central Texas, USA

\author{
Mustafa Sarıbudak $\mathbb{D}$ \\ Environmental Geophysics Associates, 2000 Cullen Ave. Austin, TX78753 Texas, USA
}

Geliş/Received : 09.01.2019 • Düzeltilmiş Metin Geliş/Revised Manuscript Received : 22.02.2019 • Kabul/Accepted : 01.03.2019 • Bask1/Printed : 15.04 .2019 Araştırma Makalesi/Research Article Türkije Jeol. Bül. / Geol. Bull. Turkey

Öz: Teksas'ın merkezinde yer alan Edwards akiferi üzerinde yapılan hidrojeolojik araştırmalarda kullanılan jeofizik yöntemler önemli bir bileşen olmuştur. Jeolojik yapıyı ve stratigrafiyi haritalamak, gömülü obrukların ve mağaraların yerlerini tespit etmek için çeşitli elektrik ve elektromanyetik yöntemler kullanılmıştır. Jeofizik yöntemler ayrıca Balcones Fay Zonu'nda (BFZ) yer alan fayları ve kırıkları tanımlayabilmek için de kullanılmıştır. Austin bölgesindeki Edwards akiferi boyunca altı ayrı sahada yürütülen çalışmalar, gömülü mağaraların ve obrukların konumları ile bölgedeki fay karakterizasyonlarının iki boyutlu (2B) ve üç boyutlu (3B) özdirenç ve doğal potansiyel (SP) yöntemlerinin bütünleşik kullanımı ile en iyi şekilde belirlenebileceğini göstermiştir. Yer radarı, indüksiyon polarizasyon ve sismik kırılma tomografisi gibi ilave jeofizik yöntemler kullanılarak da faylar ve karstik yapılar belirlenebilir. Bununla birlikte, yöntemlerin başarılı bir şekilde uygulanmasının bölgeye özgü olduğu belirtilmelidir; farklı bölgelerde yapılan çalışmalarda karstik yapıların araştırılmasında farklı jeofizik yöntemler farklı cevaplar verebilir ve farklı birincil jeofizik yöntemler tercih edilebilir.

Anahtar Kelimeler: Edwards akiferi, faylar, jeofizik, mağaralar, obruklar, Texas.

Abstract: Geophysical methods have been an important component of effective hydrogeologic investigations over the Edwards aquifer in central Texas. A variety of electrical and electromagnetic methods have been used to map stratigraphy and geologic structure and to locate buried sinkholes and caves. Geophysical methods can also characterize faults and fractures in the Balcones Fault Zone (BFZ). Six exemplary case studies across the Edwards aquifer in the Austin area show that the location of buried caves and sinkholes, and faul characterization are best accomplished by using a combination of 2-D and 3-D resistivity imaging and self-potential methods. Additional geophysical methods, such as ground penetrating radar, induced polarization, and seismic refraction tomography can be also used to characterize faults and karstic features. It is noted, however, that successful application of the methods is site dependent; applications in other karstic regions could respond differently to different geophysical methods and select different primary geophysical methods.

Keywords: Caves, Edwards aquifer, faults, geophysics, sinkholes, Texas.

\footnotetext{
*Yazışma / Correspondence: ega@pdq.net
} 


\section{GíRIŞ}

Merkez-güney Teksas'taki Balcones Fay Zonu'nda (BFZ) bulunan karstik Edwards akiferi 90-210 m kalınlığında petek yapıl1, gözenekli, su taşıyan bir formasyondur. Edwards Grubu ve diğer ilişkili kireçtaşlarını içerir ve üç segmentten oluşmaktadır: 1) Edwards akiferi'nin San Antonio Segmenti, batıdan kuzeydoğudaki Kyle yakınlarına kadar $225 \mathrm{~km}$ uzunluğunda kavis biçiminde bir eğri boyunca uzanmaktadır ve genişliği 8 ile $64 \mathrm{~km}$ arasında değişmektedir; 2) Barton Kaynakları Segmenti Kyle'dan güney Austin'e kadar uzanmaktadır; 3) Kuzey Segmenti ise Austin'in kuzeyine uzanmaktadır (Şekil 1).
Edwards akiferi'nin yapısal sistemi, akiferi ve ilişskili unsurları üç segment boyunca kuzeybatıdan güneydoğuya doğru uzatan ve boşaltan kademeli (en echelon) normal bir fay dizisi olan Balcones Fay Zonu (BFZ) tarafindan kontrol edilmektedir (Small vd., 1996; Ferrill vd., 2005; Ferrill ve Morris., 2008). BFZ, San Antonio şehri de dahil olmak üzere güney-orta Teksas bölgesi için başlica su kaynakları olan karstik Edwards ve Trinity akiferlerini içerir. Trinity akiferi, BFZ boyunca Edwards akiferinin altında bulunmaktadır.

Karst akiferleri, hızlı ve sıklıkla türbülanslı su akışına izin veren, kimyasal çözünme ile oluşmuş iletim hatları ve mağara yapılarından oluşan bir

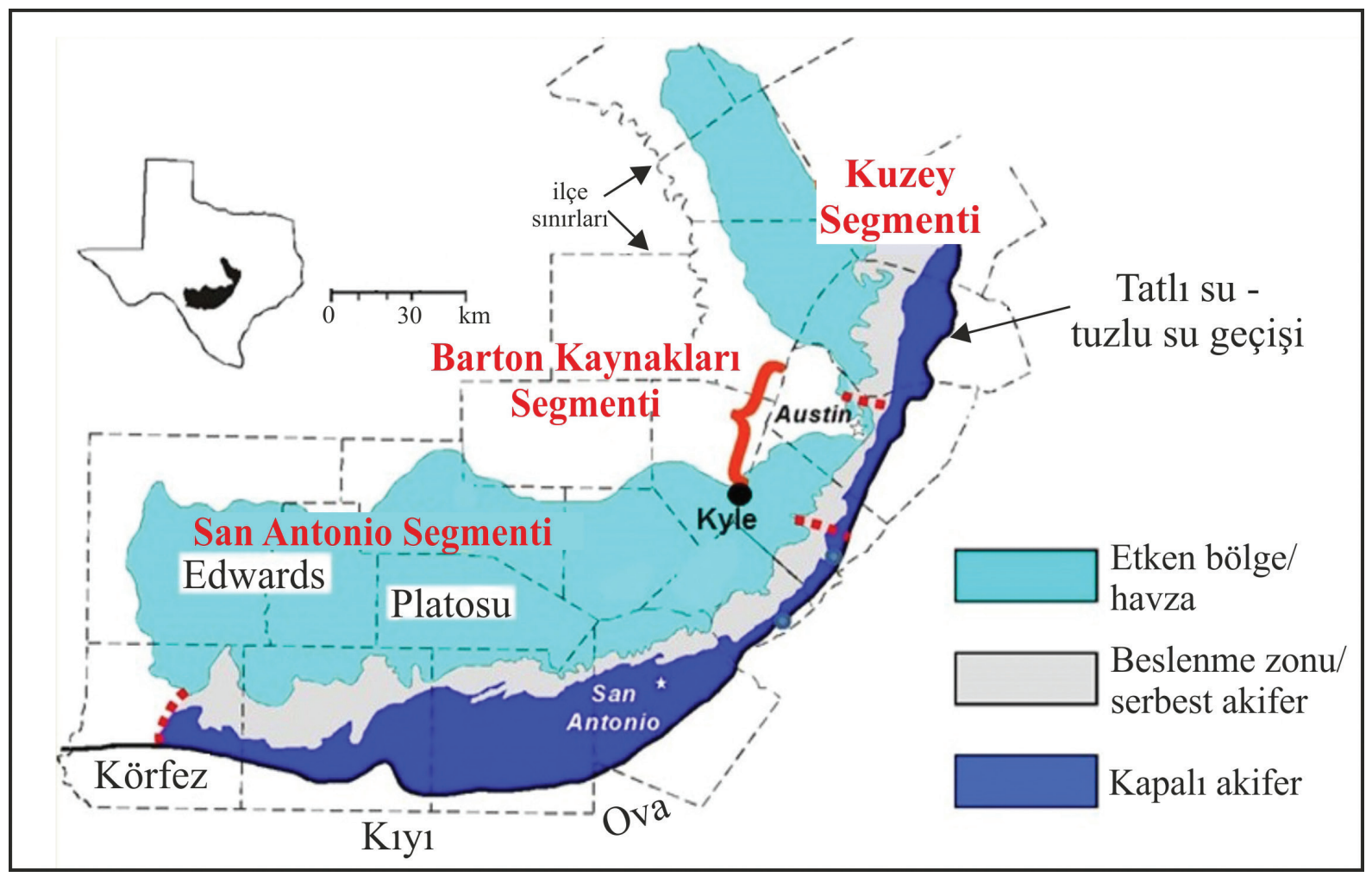

Şekil 1. Edwards akiferi'nin üç farklı segmenti arasında bulunan jeofiziksel yerlerin lokasyonları (Musgrove ve Banner, 2004'ten alınmış ve değiştirilmiştir). Austin şehri, Barton Kaynakları ve Kuzey segmenti arasında bulunmaktadir.

Figure 1. Location of geophysical sites across the three segments of Edwards aquifer (taken and modified from Musgrove and Banner, 2004). Note that the city of Austin is located between the Barton Springs and Northern Segments. 
ağ ile karakterize edilirler. Mağaralar, obruklar ve kaynaklar gibi karst yapılarının, kuyu ve hendek açma gibi geleneksel girişimsel yöntemlerle doğru bir şekilde karakterize edilmesi zordur. Bu nedenle, karstik yapılar yeraltı suyu, çevre sorunları, zemin mekaniği ve geoteknik mühendisliği açısından nitelendirilebilecek en zorlu yapılardan biridir. Jeofizik yöntemler, bu yapıların araştırılmasında bilgi sağladığı gibi, sondajlara ve karmaşık karstik yapıların detaylı araştırmalarına da rehberlik etmektedir.

Bütünleşik jeofizik yöntemler, genellikle araştırmanın amaçlarına uygun veri setleri sağlamak için sıklıkla kullanılmaktadır. Jeofiziksel bilgi, yeraltındaki mağaraların ve obrukların yerlerini saptamak, karstik oluşumlar üzerinde yapılması planlanan yapılar için tehlikeleri önceden belirlemek, yeraltı suyu kaynaklarını araştırmak ve jeolojik yapıyı karakterize etmek için kullanılabilir. Böylece jeofizik veriler, hidrojeolojik bilgi boşluklarını büyük ölçüde azaltabilir ve karstik akış sistemlerini anlamamızı kolaylaştırır.

\section{ÇALIŞMA ALANININ JEOLOJÍSİ}

Çalışma alanı, yaklaşık $2243 \mathrm{~km}^{2}$ alanında, Teksas'1n kuzeyindeki Bexar ve Comal ilçelerinde yer alan Edwards ve Trinity akiferleri'nin ve üzerini örten birimlerin (Washita, Eagle Ford, Austin ve Taylor Grupları) mostralarının içerisinde yer almaktadır. Çalışma alanındaki kayaçlar, sedimanter ve Erken Kretase dönemi yaşından Geç Kretase dönemi yaşları aralığındadır. Miyosen yaşlı Balcones fay zonu (BFZ), çalışma alanındaki birincil yapısal unsurdur. Bu fay zonu, güney-orta Teksas'ta genellikle güneybatıdan kuzeydoğuya eğilim gösteren genişlemeli bir fay sistemidir. Faylar normal düşey bileşenli, kademeli (en echelon) bir yapıya sahiptir ve çoğunlukla güneydoğuya düşmüş bloklar şeklindedir.

Erken Kretase yaşlı Edwards Grubu kayaçları, iki transgresyon hareketi sırasında, gel-git olayının yarattığ 1 düz bir sahada açık denizde birikmişlerdir. Edwards Grubu, Kainer ve Person formasyonlarından oluşur. Erken Kretase yaşın bitimine yakın yaşanan tektonik yükselme, günlenme süreci ve erozyonun ardından, günümüzdeki merkez- güney Teksas bölgesi Geç Kretase döneminde Washita Grubu'nun George- town Formasyonu'nun biriktirilmesiyle sonuçlanan denizsel transgresyon nedeniyle yeniden su altında kalmıştır. Trinity Grubu'nun üzerinde yer alan Erken Kretase yaşlı Edwards Grubu; çamurtaşı-bağlamtaş1, dolomitik kireçtaşı, arjilli kireçtaş1, evaporit, şeyl ve çörtten oluşmaktadır. Kainer Formasyonu (alttan üste doğru), bazal boğumlar, dolomitik, Kirschberg Evaporiti ve danetaşı üyelerine bölünmüştür. Person formasyonu ise (alttan üste doğru), bölgesel yoğun, ayrıştırılmış, çökmüş (bölünmemiş), döngüsel ve denizel (bölünmemiş) üyelere (Clark vd., 2016) bölünmüştür. Karstik yapıların çoğu (mağaralar ve obruklar) Edwards Akiferi'nin Kainer ve Person formasyonlarında meydana gelmiştir. Üst Glen Rose Formasyonu ve Eagle Ford Grubu, Buda Kireçtaşı ve Del Rio Kili, genellikle Edwards Akiferi'nin alt ve üst sınırlama birimleri olarak kabul edilmektedir (Şekil 2). 
Stratigrafi

\begin{tabular}{|c|c|c|c|}
\hline \multirow{3}{*}{ 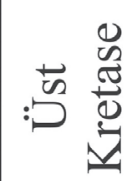 } & \multicolumn{2}{|c|}{ Eagle Ford Grubu } & \multirow{3}{*}{$\begin{array}{c}\text { Sinirlandirilmı } \\
\text { birimler }\end{array}$} \\
\hline & \multicolumn{2}{|c|}{ Buda Kireçtaș1 } & \\
\hline & \multicolumn{2}{|c|}{ Del Rio Kili } & \\
\hline \multirow{9}{*}{ 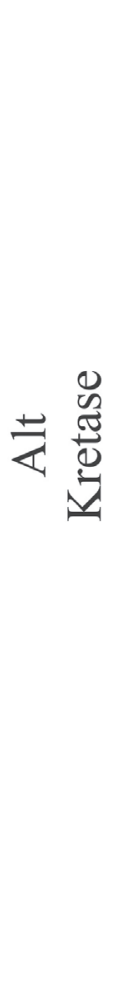 } & \multicolumn{2}{|c|}{ Georgetown Fm. } & \multirow{3}{*}{$\begin{array}{c}\text { Edwards } \\
\text { Akiferi }\end{array}$} \\
\hline & \multirow{2}{*}{ 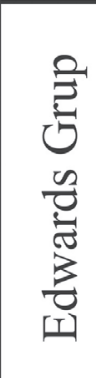 } & 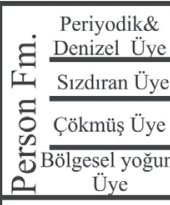 & \\
\hline & & 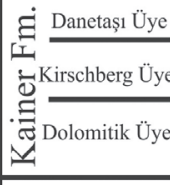 & \\
\hline & \multirow{6}{*}{ 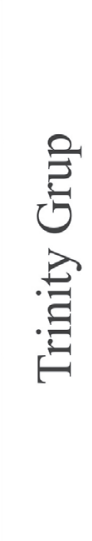 } & Üst & $\begin{array}{c}\text { Üst } \\
\text { Trinity }\end{array}$ \\
\hline & & & \begin{tabular}{|l} 
Sinirlandirlmış \\
$7^{\text {birim }}$
\end{tabular} \\
\hline & & $\begin{array}{c}\text { Alt } \\
\text { Glen Rose }\end{array}$ & \\
\hline & & Hensel & \\
\hline & & $\begin{array}{l}\text { Cow } \\
\text { Creek }\end{array}$ & \\
\hline & & Hammett & $\begin{array}{l}\text { Sinnrlandirlmils } \\
\text { birim }\end{array}$ \\
\hline
\end{tabular}

Şekil 2. Çalışma alanındaki Alt ve Üst Kretase yaşlı oluşumların stratigrafik sütunu, Edwards`ın ve altta bulunan Trinity Gruplarının hidrostratigrafik üyelerini göstermektedir (Rose, 1972, Small vd., 1996). Üst Glen Rose Formasyonu kismen bir akitard olarak yorumlanmaktadır (Wong vd., 2014).

Figure 2. The stratigraphic column of the Lower and Upper Cretaceous formations within the study area illustrating hydrostratigraphic members of the Edwards and underlying Trinity Group (Rose, 1972, Small vd., 1996). Note that the Upper Glen Rose Formation is partly interpreted as an aquitard (Wong vd., 2014).

\section{YÜZEY JEOFİŻĞİ YÖNTEMLERİ}

Jeofizikyöntemleryeraltınıkeşfetmekiçinkulanılan güçlü araçlardır. Uygulamalar arasında hidrolojik ve hidrojeolojik karakterizasyon, boşlukların ve karstik yapıların yerlerinin belirlenmesi, toprak karakterizasyonu ve kirlilik değerlendirmesi bulunur. Çok kanallı yüzey dalgası analizi yöntemi ile birlikte sismik kırılma gibi teknolojiler son on yılda artarak kullanılmalarına rağmen, iki boyutlu (2B) ve üç boyutlu (3B) özdirenç kesiti, doğal potansiyel (SP), yer iletkenlik (EM-31 ve 34), gravite ve manyetik yöntemler daha yaygın olarak kullanılmaktadır. Mevcut teknikler, birkaç metreden kilometreye kadar farklı derinliklerde penetrasyon ve çözünürlük özellikleri sunarlar. $\mathrm{Bu}$ sebeple, yeraltının farklı fiziksel özelliklerin analizi için birden çok jeofizik yöntem bütünleşik olarak kullanılmaktadır (Çizelge 1).

Jeofizik yöntemleri, Teksas'ın merkezinde yer alan Edwards akiferi'nin hidrojeolojik incelemesinde etkili bir bileşeni olmuştur. Başlica ana akifer sistemlerinde stratigrafiyi, jeolojik birimleri ve su tablasının derinliğini haritalamak için elektrik ve elektromanyetik yöntemlerin bütünleşik olarak kullanılmıştır (Fitterman ve Stewart, 1986; Connor ve Sandberg, 2001). Jeofizik yöntemler aynı zamanda karst yapılarının (mağaralar, boşluklar, kırıklar ve faylar) konumlarını belirlemek için de kullanılmıştır (Gary, vd., 2013; Shah, vd., 2008; Smith, vd., 2005; Blome, vd., 2008; Saribudak, 2011; Saribudak, vd., 2012a; Saribudak, vd., 2012b; Saribudak, vd., 2013; Saribudak, 2015, Saribudak, 2016; Saribudak ve Hauwert, 2017). 
Çizelge 1. Karstik özellikler ve fayların karakterize edilmesinde kullanılan geleneksel jeofizik yöntemler.

Table 1. Traditional geophysical methods used in characterizing karstic features and faults.

\begin{tabular}{|l|l|}
\hline Yöntem & Ölçülen parametre \\
\hline Özdirenç & Yeraltına iletilen elektrik akımına karşılık oluşan potansiyel fark \\
\hline Doğal Gerilim & Yeryüzündeki doğal akımlardan kaynaklanan elektrik potansiyelleri \\
\hline Yer Radarı & Yansıyan EM enerjisinin varış zamanı ve genliği \\
\hline İletkenlik & Yeraltındaki iletkenler nedeniyle indüklenen manyetik alanlar \\
\hline Gravite & Yerçekimi ivmesinin düşey bileşeni \\
\hline Manyetik & Dünya’nın manyetik alanının büyüklüğü ve/ veya gradyanı \\
\hline IP & Yeraltına iletilen akımın kesilmesi ile elektirik potansiyelinde düşüş \\
\hline Sismik & Kırılan elastik enerjinin genliği ve varış zamanı \\
\hline
\end{tabular}

$\mathrm{Bu}$ çalışmada, Edwards kiferi'ndeki 6 araştırma sahasına ait sonuçlar sunulmuştur. Araştırmalar sahaları Austin bölgesindedir ve Balcones Fay Zonu'nun (BFZ) içinde bulunmaktadır. $\mathrm{Bu}$ çalışmanın amacı, bütünleşik jeofizik yöntemlerin genel olarak Edwards akiferi'nin hidrostratigrafisi ve özellikle BFZ içindeki karstik yapılar, faylar ve kırıklı yapılar ile ilgili nasıl önemli bilgiler sağlayabileceğini göstermektir.

Türkiye'de ise karstik oluşumların araştırılmasına yönelik yapılmış olan çalışmalara örnek olarak Balkaya vd.,'nin (2012) Ayvacık Düdeni civarındaki çalışmaları verilebilir. $\mathrm{Bu}$ çalışmada karstik boşlukların araştırılmasında manyetik ve 2B düşey elektrik sondajı (DES) yöntemleri kullanılarak kireçtaş1-mağara sisteminn dokanak yüzeyi saptanmış ve yüksek özdirenç anomalisi veren karstik boşluk belirtisi elde edilmiştir. Bir başka çalışma örneği ise Uçar ve Aktürk'ün (2015) Antalya Masa Dağ1 bölgesindeki yeraltı boşluklarını tespiti için yapmış olduğu 2B elektrik özdirenç ölçümleridir.

Bu çalışmada, doğal potansiyel (SP), özdirenç tomografi, sismik kırılma tomografi, indüklem polarizasyon (IP) ve yeralt1 radarı yöntemi (GPR) kullanılmıştır. Kullanlan yöntemlere ait kısa bilgilendirmeler aşağıda verilmiştir.

\section{Self Potential (SP)}

Doğal gerilim (SP), yeryüzünde ölçüm noktasının yakınında elektrik potansiyellerinin bulunmasına neden olan jeolojik, jeokimyasal ve hidrolojik etkileşimlerden kaynaklanan ve doğal olarak ortaya çıkan elektrik potansiyelidir (Lange ve Kilty, 1991, Lange, 1999, Vichabian ve Morgan, 2002, Revil ve Jardani, 2013).

SP yöntemi pasif, müdahalesiz ve elektrik akımı uygulaması gerektirmez. Doğrudan temas halinde olan farklı konsantrasyonlardaki iki elektrolitik çözelti ve yer altı suyunun gözenekli maddelerden akmasıyla (akış potansiyeli) birkaç millivoltluk sıra halinde küçük potansiyeller üretilir. Yavaş yavaş değişen doğru akımlar (D.C.), mağaralar ve obruklar gibi karstik özelliklerin belirlenmesine yardımcı olan geçirimli malzemeler içinde yeraltı suyu akışı nedeniyle doğal potansiyellerin yüzey dağılımına yol açar (Saribudak, 2016, Saribudak ve Hauwert, 2017).

Bir doğal potansiyel yöntemi, bir çift elektrot ile birlikte bir baz istasyonunun kullanılmasını içerir. Baz istasyonu, bir makara üzerindeki gezici istasyonuna bağlanmıştır. Voltmetrenin doğruluğu $0.1 \mathrm{mV}$ değerinde kaydedilmiştir. İstasyon veri noktaları SP profillerinde dolu daireler şeklinde gösterilmektedir. 


\section{Elektrik Özdirenç Tomografi Yöntemi}

2B özdirenç yöntemi, zemine iki akım elektrodu boyunca sabit bir akım uygulayarak ortaya çıkan gerilim farklarını iki potansiyel elektrotta ölçülmesi ile yeraltını inceler. Elde edilen görünür özdirenç değeri, ölçülen özdirencin ve seçilen bir elektrot dizilimi için uygulanan geometrik düzeltmenin bir ürünüdür. Özdirenç değerleri (ohm-m), ortamdaki su veya nem varlığ1, malzemedeki gözenek boşluğu miktarı, dağılımı ve sıcaklık gibi değişkenlerden yüksek oranda etkilenir (Rucker ve Glaser, 2015). Arazi ölçümleri sirasinda The Advanced Geosciences, Inc. (AGI) şirketine ait SuperSting R1 cihazı ile dipol-dipol dizilim kullanılarak ölçüm alınmıştır. 2B/3B elektrik özdirenç kesitleri Advance Geoscience's EarthImager 2D/3D yazılımı kullanılarak elde edilmiştir. Veri toplama aşamasından önce her bir profil için kontak direnci testi yapılmıştır. Kontak direnci testi, elektrotlar ile yer yüzeyi temasının sorunlu olup olmadığını kontrol etmek için yere gönderilen akımın her bir elektrot için test edilmesidir. Yüksek veya çok değişken elektrot temas direnci değerleri nedeniyle düşük veri kalitesi veya veride anormal değerler elde edilebilir. $\mathrm{Bu}$ nedenle kontak direnci testinden öne ölçüm profilleri boyunca her bir elektrota tuzlu su çözeltisi eklenerek kontak direnci etkisi azaltılmıştır.

AGI EarthImager 2D programı özdirenç verilerinden $2 \mathrm{~B}$ ters çözüm modellemesi için kullanılan bir programdir (EarthImager 2D Manual, 2002-2014). Bu program ile arazide toplanan verilere ters çözüm yöntemi uygulanarak 2B eletrik özdirenç kesiti elde edilmiştir.

\section{Sismik Kırılma Tomografi Yöntemi}

Sismik kırılma yöntemi, yanal ve düşey yöndeki sismik hız ve / veya katman kalınlığı değişikliklerini tanımlar ve tabakalı bir jeolojik sahada en iyi sonucu verir. Sismik Kırılma yöntemi için en önemli olanı, sismik dalgaların içinde yayılma hızı en yüksek olan $\mathrm{P}$ dalgası enerjisidir (Chen ve Zelt, 2016). Bir P dalgası yeryüzünde ilerledikçe, geçtiği her parçacığı, bir dizi sıkıştırma ve genişletme hareketiyle yayılma yönüne paralel yönde hareket ettirir (Parasnis, 1996). Kırılma yöntemi, yalnızca hızı derinlikle artan katmanları görmektedir.

Arazi çalışmasında veriler Geometrics Geode cihazı kullanılarak 3 metre jeofon aralığ 1 ile dizilmiş 24 adet jeofon ile toplanmıştır. Sismik enerji kaynağı olarak 6.5 kilogram ağırlığında bir balyoz kullanılmıştır. Profil boyunca farklı ofset mesafelerinde toplam 11 adet atış yapılmıştır. Sinyal/gürültü oranını arttırmak amaciyla her ofset noktasında 5 vuruş yapılarak veri toplanmıştır. Sismik kırılma veri işlemi için Intelligent Resources, Inc. tarafindan sağlanan Rayfract yazılımı içindeki 1şın-izleme algoritması kullanılmıştır ve Golden Surfer programı ile sismik kırılma tomografi kesiti çizilmişitir.

\section{Yeraltı Radarı Yöntemi (GPR)}

Yeraltı Radarı Yöntemi'nde (GPR) 400 megahertz $(\mathrm{MHz})$ anten kullanılarak 3 metre araştırma derinliğine kadar veri toplanmıştır. GPR, 1 ile 1000-megahertz (MHz) frekans aralığındaki radyo dalgalarını kullanan tekniklere verilen genel isimdir. $\mathrm{Bu}$ yöntem, yüzeye yakın jeolojiyi ve insan-yapımı birimleri haritalamak için kullanılır (örneğin, Freeland, 2015; Freeland vd., 2016; Lachlab vd., 2015).

GPR sistemi, verici ve alıc1 antenlerinden ve renkli bir ekran ünitesinden oluşur. Radyo dalgalarının derinlik penetrasyonu yerin iletkenliğine ve seçilen antenin özelliklerine bağlı olarak değişir. Frekans yükseldikçe ve kullanılan anten küçüldükçe arama derinliği sığlaşmaktadır. Yeraltındaki malzemesinin elektrik iletkenliği, radar sinyallerinin derinlik penetrasyonunu belirler. Topraklarda ve gözenekli kayaçlarda 
elektriksel iletkenlik, su içeriği, kil içeriği ve gözenekli suyun iletkenliği ile yönetilir (Rucker ve Ferre, 2004). Arazide toplanan GPR verilerinin işlenmesi için Jeofizik Araştırma Sistemi A.Ş.' ait (GSSI) Radan 7 yazılımı kullanılmıştır. GPR verisine temel gürültüleri kaldırmak için sadece background removel filtre uygulanmıştır.

\section{İndüklem Polarizasyon (IP)}

Zamanın bir fonksiyonu olarak azalan potansiyel farkının ölçülmesi, zaman ortamında İndüklem Polarizasyon (IP) yöntemi olarak bilinmektedir.

$\mathrm{Bu}$ yöntemde yere uygulanan akımın kesilmesinden sonra yerden alınan gerilimin hemen sıfır olmadığı, ancak belli bir değerden itibaren sıfır değerine ulaştığı izlenir. İndüklenem polarizasyon metodu cevher araştırmalarında yaygın olarak kullanılmaktadır (Parasnis, 1996). Bu yöntemin jeoteknik ve mühendislik uygulamalarında kullanımı sinırlıdır ve temel olarak yeraltı suyu araştırmalarında kullanılır. Arazide özdirenç ölçümlerinin alındığı sırada aynı zamanda IP verisi de toplanmıştır. IP ölçümlerinde kullanılan birim milisaniye cinsindendir.

\section{ÖRNEK SAHA ÇALIŞMALARI}

$\mathrm{Bu}$ çalışmada sunulan altı araştırma sahası; jeofizik yöntemlerin, fayların ve karstik özelliklerin (mağaralar ve obruklar) yerlerinin belirlenmesinde ve BFZ tarafindan sinirlanan Edwards akiferi'nin stratigrafi haritasınının ve jeolojik yapısınının oluşturulmasında etkili bir şekilde kullanılabileceklerini göstermeyi amaçlamaktadır (Şekil 3).

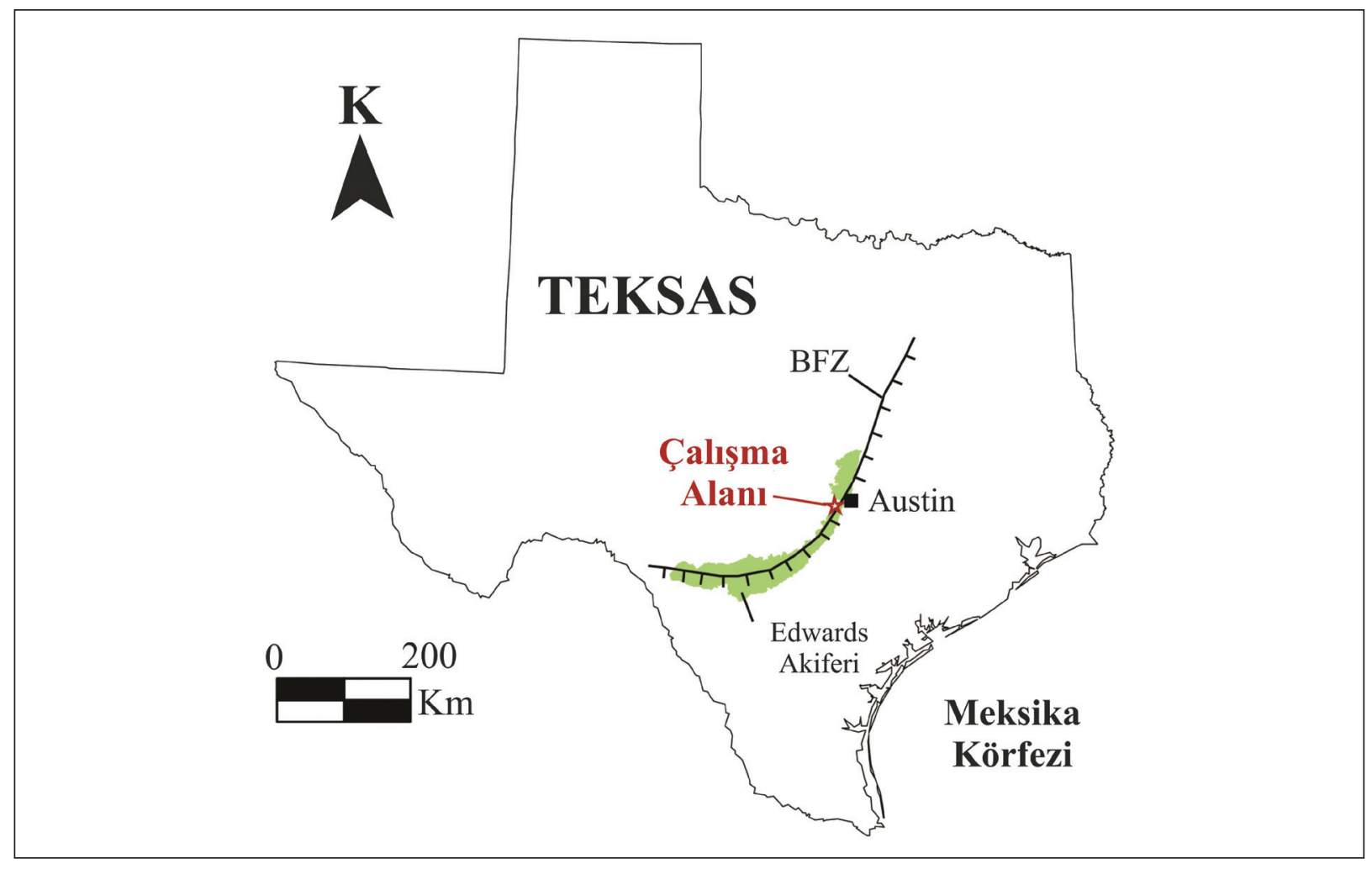

Şekil 3. Teksas'ın merkezinde yer alan Edwards akiferi ve Balcones Fay Zonu'nu (BFZ) gösteren harita.

Figure 3. Map showing the Edwards aquifer and Balcones Fault Zone (BFZ) in central Texas. 


\section{Araştırma Sahası: Ana Barton $\mathrm{Su}$} Kaynağı'ndaki Barton Kaynak Havuzu İletim Hatt1

Barton Kaynak Havuzu, eğlence amaçlı kullanılan ve çevresindeki doğal su kaynaklardan beslenen bir açık yüzme havuzudur. Bu havuz Austin, Teksas'taki Zilker Park'ında yer almaktadır. Havuz, Barton deresindeki kanal içerisinde bulunmaktadır ve Teksas'taki dördüncü büyük kaynak olan Ana Barton su kaynağından gelen suyu kullanmaktadır (Şekil 4).

Ana Barton su kaynağı, Teksas Austin Zilker Parkı'ndaki Edwards akiferi'nin önemli bir boşaltma alanı olarak yer almaktadır.
Barton Kaynakları en az dört su kaynağından oluşmaktadır. Ana Barton su kaynağı dişında fayların batısındaki havuzun zemininde yer alan, birçok çatlaklar ve çakıllarla dolu çözelti oyukları ve bir mağara boyunca birçok çıkış noktalarından gelen malzemeler Barton Kaynakları havuzuna akarlar Hauwert, 2009). Ana Barton su kaynağ 1 bölgesinin yüzey jeolojisi, Edwards akifer birimlerini (bölgesel yoğun ve sızdıran çökmüş üyeler) ve Georgetown Formasyonunu içerir (Hauwert, 2009). Barton Kaynakları Fayı, Edwards Grubu birimleri ile Georgetown Formasyonuna ait birimleri yan yana koymaktadır. Barton Kaynak havuzunun havadan görüntüsü ve şematik jeolojik kesiti (Young,1974) Şekil 5'de verilmektedir.

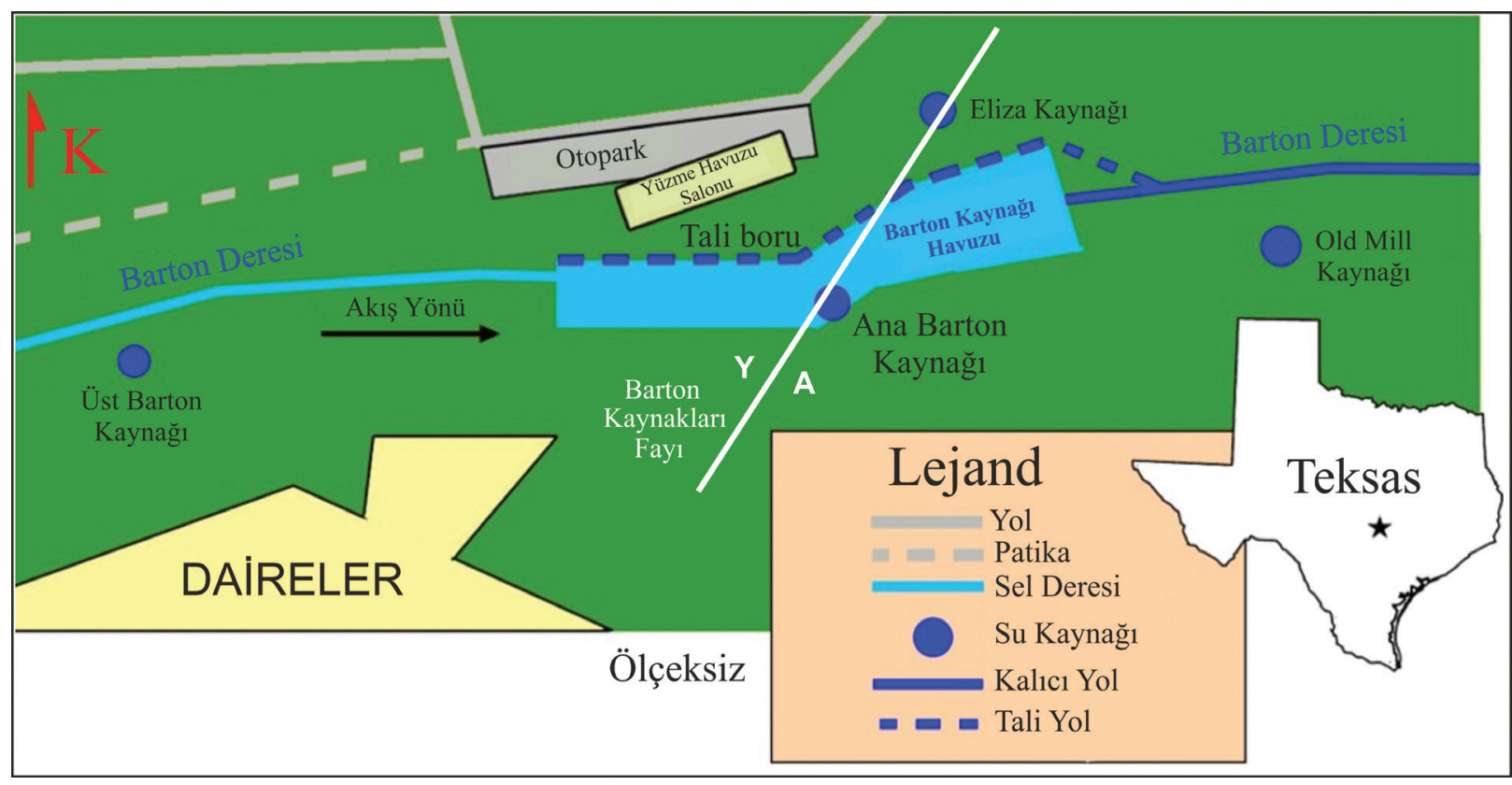

Şekil 4. Barton Kaynağı yüzme havuzunun şematik haritası. Barton Deresi'nin yüzey suyu yeraltı borusu yardımıla kuzeye yönlendirilmiştir. Ana Barton Kaynağı'ndan gelen bu yeraltı suyu yüzme havuzuna doğrudan boşalmaktadır. Barton Kaynakları Fayı, Ana Barton Kaynağı'nı kuzeydoğu-güneybatı yönünde kesmektedir. Eliza ve Old Mill Kaynakları'nda da jeofizik çalışmalar yapılmış ve sonuçlar Saribudak vd., 2013'de yayınlanmıştır.

Figure 4. Schematic map of the Barton Springs Swimming pool. Note that the surface water of Barton Creek was diverted via an underground pipe to the north. The groundwater from the Main Barton Springs discharges into the swimming pool. Note that the Barton Springs fault crosses the Main Barton Springs in the northeast-southwest direction. Geophysical studies were also conducted on Eliza and Old Mill Springs and results were published in Saribudak vd., 2013. 
Austin, Teksas’taki Barton Kaynak havuzu civarında birçok jeofiziksel araştırma yapılmıştır (Saribudak vd., 2013; Saribudak ve Hauwert, 2017).

Zilker Parkı yüzme havuzunun güney çit sınırı boyunca doğu-batı uzanımlı profil boyunca elektrik özdirenç (2B ve 3B), doğal potansiyel (SP), indüksiyon polarizasyon (IP) ve tomografik sismik kırılma çalışmaları gerçekleştirilmiştir (Şekil 6). Yüzme havuzunda yaşayan nesli tükenmekte olan Semender türlerinin etkilenmemesi için doğal potansiyel (SP) verileri yüzme havuzunun yakın çevresinde toplanmıştır (Şekil 6, S1 profili).

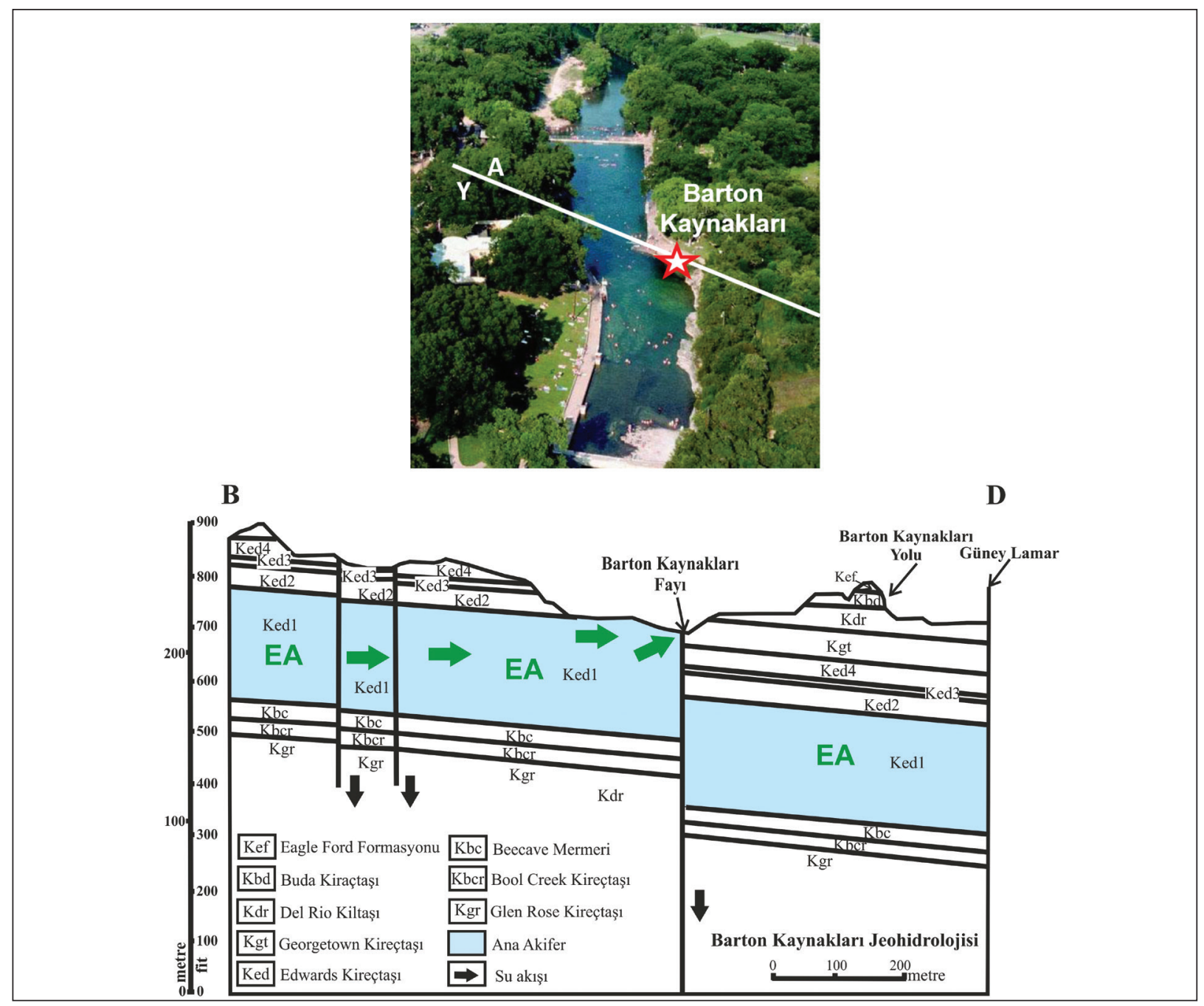

Şekil 5. (a) Barton Kaynak havuzunun havadan görüntüsü ve (b) Edwards akiferi (EA) içindeki yer altı suyunun (yeşil oklar) batıya doğru akışının Barton Kaynakları Fayı ile sonlandırılıncaya kadar nasıl aktığını gösteren şematik jeolojik kesit (Prof. Dr. Keith Young'ın izni ile,1974).

Figure 5. An aerial view of the Barton Springs pool (a) and the schematic geological cross-section suggesting how groundwater flows (green arrows) within the Edwards Aquifer (EA) from the west direction until its flow is terminated by the Barton Springs fault (Courtesy of Prof. Dr. Young, 1974). 
SP verilerine ait sonuçlar Şekil 7'de verilmiştir. Güney yakasındaki SP verilerinde, düşük SP anomalisi (A1) $60 \mathrm{~m}$ istasyonunda görülmektedir. $\mathrm{Bu}$ anomali, Barton Kaynakları Fayı'nın havuzdan geçtiği yere karşı1lı gelmektedir (Şekil 7). Bu anomalinin kaynağ 1 bir mağara olarak yorumlanabilinir. SP verileri, 75 ve 120 m istasyonları arasında yüksek SP anomalisini (A2) işaret etmektedir.

Karşılaşılan bu önemli SP anomalisi varlığı bize Zilker Parkı'nın güneyinde, havuzun disinda birden fazla jeofizik yöntemin (özdirenç, IP, sismik kırılma tomografisi) uygulanması gerektiğini göstermektedir (Şekil 8).

Çalışma alanında yapılan özdirenç ölçümlerinden elde edilen özdirenç kesit (Şekil 8a), yaklaşık 10 m'lik derinlikte önemli bir düşük özdirenç anomalisini (mavi renk) göstermektedir.
Profil üzerinde Zilker Park1'nın güney kap1 girişi referans olarak belirtilmiştir. Anomali 10 $\mathrm{m}$ genişliğe sahiptir ve doğuya doğru bir dalma olduğu görülmektedir.

Düşük özdirenç anomalisinin su ve/veya bir karst yapısı içindeki kil varlığının birleşiminden kaynaklandığı yorumlanmaktadır. Aynı profil üzerinde alınan IP ölçümlerinden elde edien kesitte (Şekil 8b) yüksek anomali değerleri düşük özdirenç anomalisinin görüldüğü lokasyonda (kırmızı renk) bulunmaktadır. IP profilinde gözlenen anomalinin kil oluşumları ve/veya sülfit partikülleri gibi mineralleşmelerden kaynaklandığ 1 yorumu yapılabilir.

$\mathrm{Bu}$ anomalinin lokasyonu, Ana Barton su kaynă̆ı'nın havuza boşaldı̆̆ı yere daha yakındır. Dolayısıyla, bu SP anomalisinin kaynağı yer altı suyunun havuza boşalmasıyla ile ilişkili olabilir.

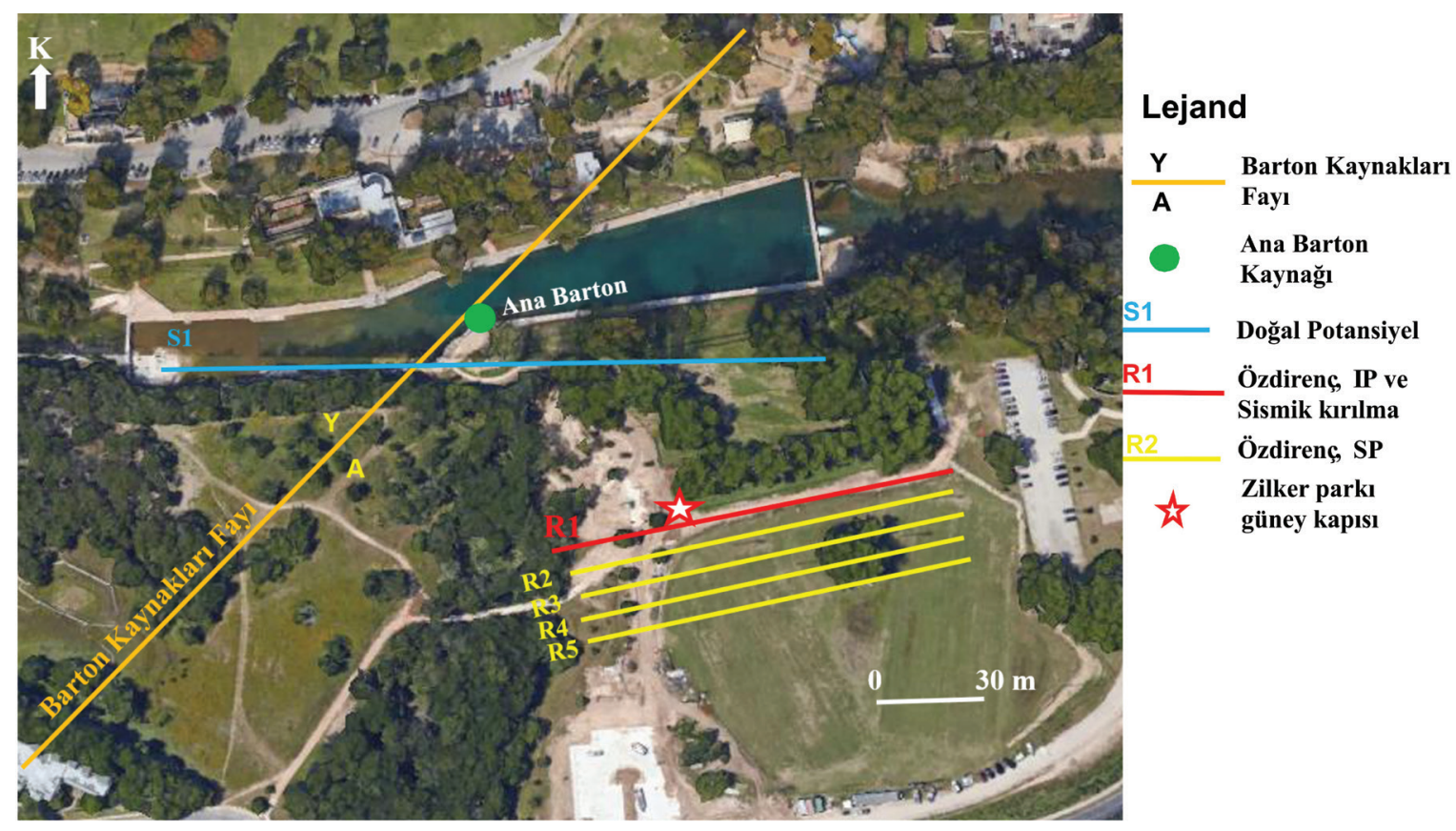

Şekil 6. Barton Yüzme havuzunun güneyindeki özdirenç, SP, IP ve sismik kırılma çalışmalarının lokasyonlarını gösteren havadan bir harita. Bu çalışmada sadece özdirenç profili R1” tartışılmıştır. R2 ile R5 arasındaki özdirenç profillerine ait sonuçlar Sarıbudak vd., 2013 ve Sarıbudak ve Hauwert, 2017'de yer almaktadır.

Figure 6. An aerial map showing locations of resistivity, SP, IP and seismic refraction surveys in the south part of the Barton Swimming pool. Only the resistivity profile R1 was discussed in this paper. Resistivity profiles 22 through R5 can be accessed from Saribudak vd., 2013, and Saribudak and Hauwert, 2017. 


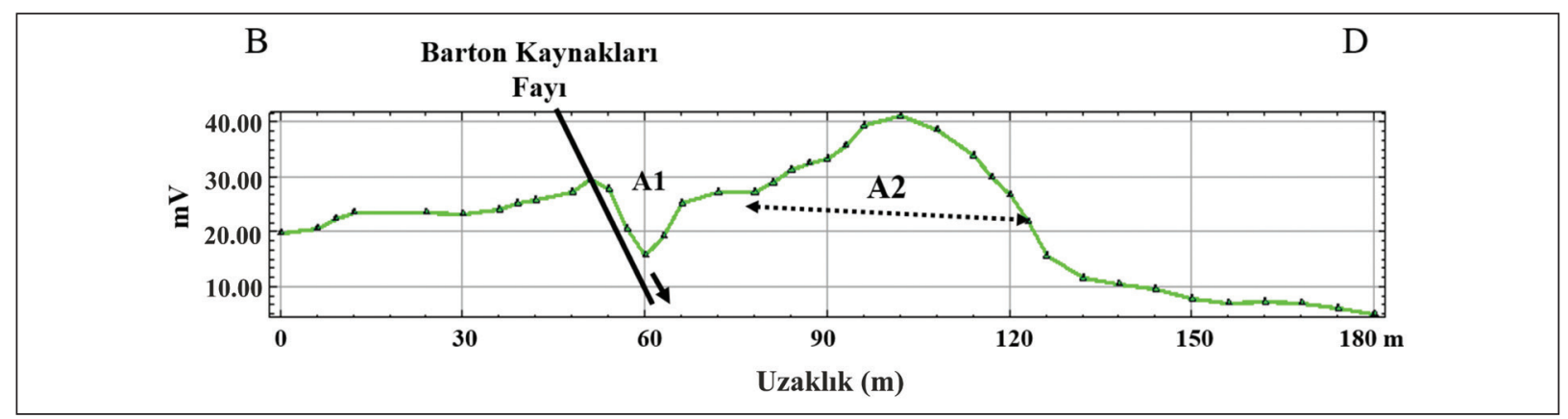

Şekil 7. Yüzme havuzunun güney kıyısındaki S1 profili boyunca elde edilen SP verileri.

Figure 7. The SP data along profile S1 along the southern bank of the swimming pool.

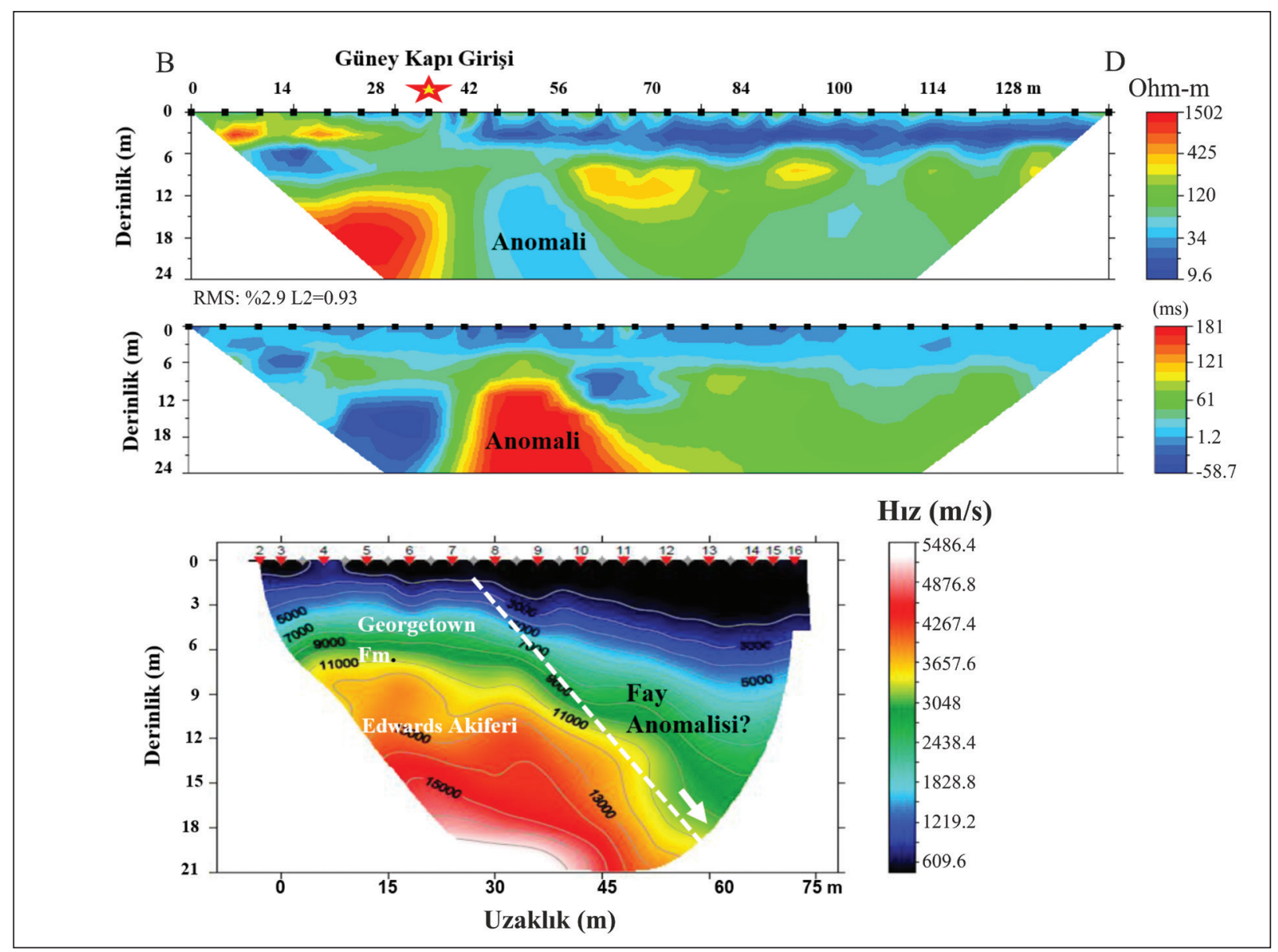

Şekil 8. Barton Kanağı’nda (a) elektrik Özdirenç, (b) IP ve (c) sismik kırılma çalışmalarından elde edilen sonuçlar. Kesitlerde gözlenen düşük özdirenç, yüksek IP ve olası fay yapısı dikkat çekmektedir. Fayın yönü Barton Kaynağı Fayı ile oblik açı1ı kesişmektedir.

Figure 8. Results from the (a) electrical resistivity, (b) IP, and (c) seismic refraction surveys at Barton Springs. Note the low resistivity, high IP and a fault-like anomaly along the profiles. The trend of the fault intersects obliquely with the Barton Springs fault. 
Sismik kırılma kesiti ise jeolojik birimleri (Edwards akifer birimleri ve Georgetown Formasyonu) tanımlamakla birlikte, olası fay anomalisini de göstermektedir (Şekil 8c). Bu fay anomalisi daha önce çalışma alanında yapılmış olan iletkenlik (EM31) ve GPR ölçümlerinde de gözlenmiştir (bkz. Saribudak vd., 2013 ve Saribudak ve Hauwert, 2017). Bu araştırmalardan elde edilen önemli sonuçlardan biri de, tüm profillerde gözlenen ortak bir anomalinin varlığ1 olmuştur. Anomalilerin gözlendiği lokasyon ile Ana Barton Su Kaynăğ'nın dejarj lokasyonu birbiriyle ilişkilidir.

R1 profili dışında, bu profile paralel D-B uzanımlı dört hat üzerinde de özdirenç ölçümleri alınmıştır. $\mathrm{Bu}$ yayında bu hatlara ait sonuçlar verilmemiştir ancak Saribudak ve Hauwert, 2017'de detaylıca tartışılmıştır. Ancak burada, R1 özdirenç profili ve daha önce yayınlanmış diğer dört adet D-B uzanımlı özdirenç profili kullanılarak 3B özdirenç blok diyagramı oluşturulmuştur (Şekil 9a). R1 profili boyunca toplanan SP profili ise Şekil 9b'de verilmektedir. Üç boyutlu yapmakesit üzerinde yüksek SP anomalisinin görüldüğü sınırlarda belirgin düşük bir özdirenç zonu dikkat çekmektedir.

Özetle, tüm jeofizik verilerin sonuçları, bölgedeki bir iletim hattının varlığına ait anomaliyi ve yüzme havuzu güney kapı girişinin yakınında yer alan ve Ana Barton su kaynağı'nın Barton Kaynağ1 Yüzme havuzuna aktığ 1 yerle yaklaşık olarak aynı hizada yer alan yeni keşfedilmiş bir fayı göstermektedir (Şekil 9). Ana Barton su kaynağı'na yeraltı suyu akış yönü jeofizik anomalilerin olduğu lokasyonları takip etmekte ve yüzme havuzuna deşarj olmaktadır.

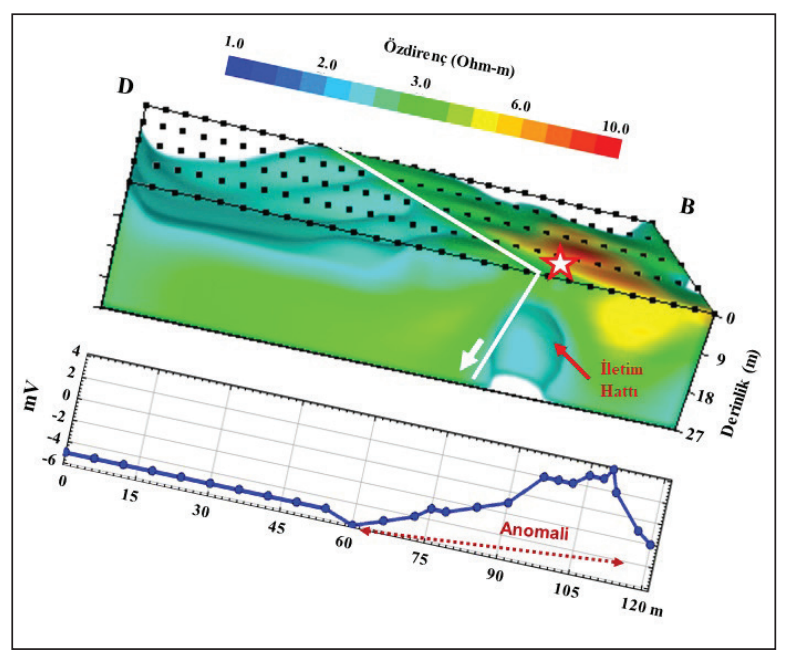

Şekil 9. (a) Üç boyutlu (3B) özdirenç yapma- kesiti ve (b) SP profili Zilker Park'ın güneyinde bir iletim hattı ve olası fay anomalisinin olduğunu göstermektedir. Kırmızı yıldız sembolü, havuzun güney kapı girişinin yaklaşık olarak konumunu göstermektedir Şekillerin yönü, anomalilerle uyumlu olması adına batı-doğu'dan ve doğu-batı'ya çevrilmiştir.

Figure 9. (a) A pseudo 3-D resistivity block and (b) the SP data indicating a conduit-and fault-like anomaly in the south of the Zilker Park. The red star symbol shows the approximate location of the south gate entrance to the pool. Note that the direction of the figures was switched from the west-to-east to the east-to-west for proper illustration of the anomalies.

\section{Araştırma Sahası: McNeil Mağarası}

Austin Şehri Havza Koruma Dairesi, Martin Tepesi İletim Hattı'nın (MHTM) tasarımı ve inşaat projesi için Edwards akiferi'nin kuzey segmenti üzerindeki deşarj alanında hidrojeolojik bir araştırma yaptırmıştır. Bu deşarj alanında, birden çok karstik yapıya rastlanmıştır; McNeil Lisesi kuzeyinde obruk/mağara yapısı, doğusunda McNeil Yarasa Mağarası, batısında ise iki Weldon ve No Rent Mağarası bulunmaktadır. Bölgede farkl1 jeofizik yöntemler (elektrik özdirenç, SP, GPR, manyetik ve yer iletkenlik) kullanılarak araştırma yapılmıştır (Sarıbudak, 2015). Burada Martin Tepesi İletim Hattı (MHTM) ve Weldon Mağarası civarında yapılmış olan özdirenç ve SP ölçümlerinin sonuçları tartışılacaktır. 


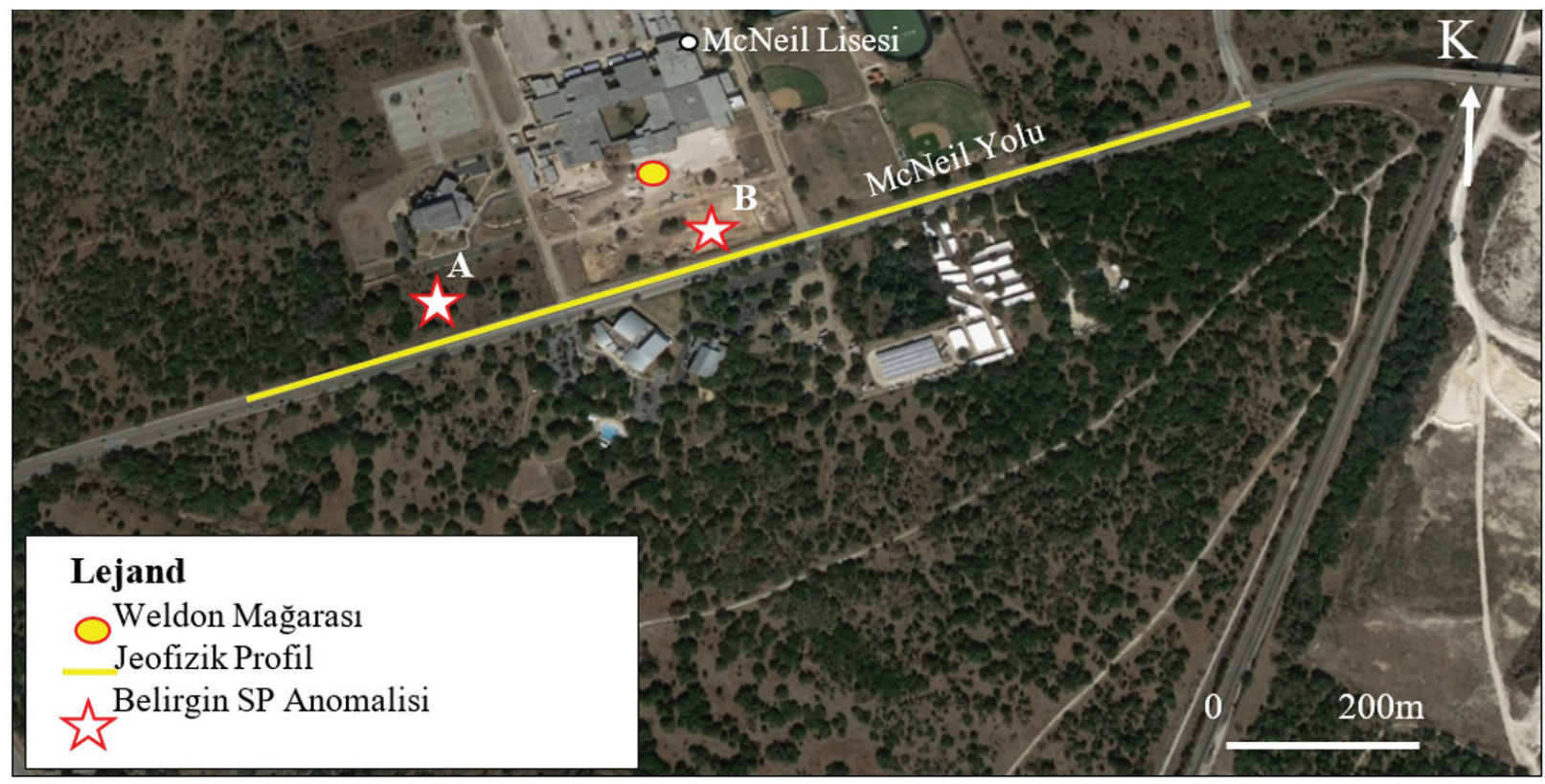

Şekil 10. McNeil Yolu boyunca alınan jeofizik profil (özdirenç ve SP) için yer bulduru haritası.

Figure 10. Site map indicating the location of geophysical profile (resistivity and SP) along McNeil Drive.

Weldon mağarası çalışma alanının KB sınırında yer almaktadır. Çalışma alanının batısında alınan özdirenç ve SP ölçümlerine ait kesitler Şekil 11'de verilmiş. Özdirenç kesiti, profil boyunca düşük özdirençli bir katman altında ondülasyonlu bir yapıya sahip yüksek dirençli bir katmanın varlığını göstermektedir. Profil boyunca çarpıcı bir özdirenç anomalisi gözlenmemektedir (Şekil 11a). Ancak SP kesiti incelendiğinde (Şekil 11b) yatay genişliği 60 metre olan ve $30 \mathrm{mV}$ 'luk potansiyel değerine ulaşan belirgin bir SP anomali (A) görülmektedir.

McNeil Lisesi'nin doğusunda alınan özdirenç ve SP ölçümlerinden elde edilen sonuçlar Şekil 12'de verilmektedir. Özdirenç kesiti incelendiğinde bölgede karstik bir yapının varlığından söz edilemez (Şekil 12a). Ancak Şekil 12b'de verilen SP kesiti üzerinde profil üzerinde 121 ve $168 \mathrm{~m}$ istasyonlar arasında kalan ve "B" harfi ile işaretlenmiş alanda büyüklügü yaklaşı 40 mV'a ulaşan belirgin bir SP anomalisi görülmektedir. Anomalinin görüldüğü lokasyonda bulunan mağaranın girişine ait resim Şekil 12c'de verilmiştir. Ayrıca, bu mağaraların varlığı 2014 yılının yaz ve sonbahar aylarında bölgede yapılan inşaat faaliyetleri sırasında da ortaya konmuştur. Bölgede çalışan iş makinaları $6 \mathrm{~m}$ derinliğe kadar kazı yaparak su iletim hattına ulaşmışlardır. $\mathrm{Bu}$ kazılar esnasında, SP kesitlerinde "A" ve "B" olarak etiketlenen alanlarda 5 metre derinlikte iki adet mağaraya ulaşmışlardır Her iki mağara, Edwards akiferinin Kainer Formasyonu içinde gelişmiştir (bkz. Şekil 2). 


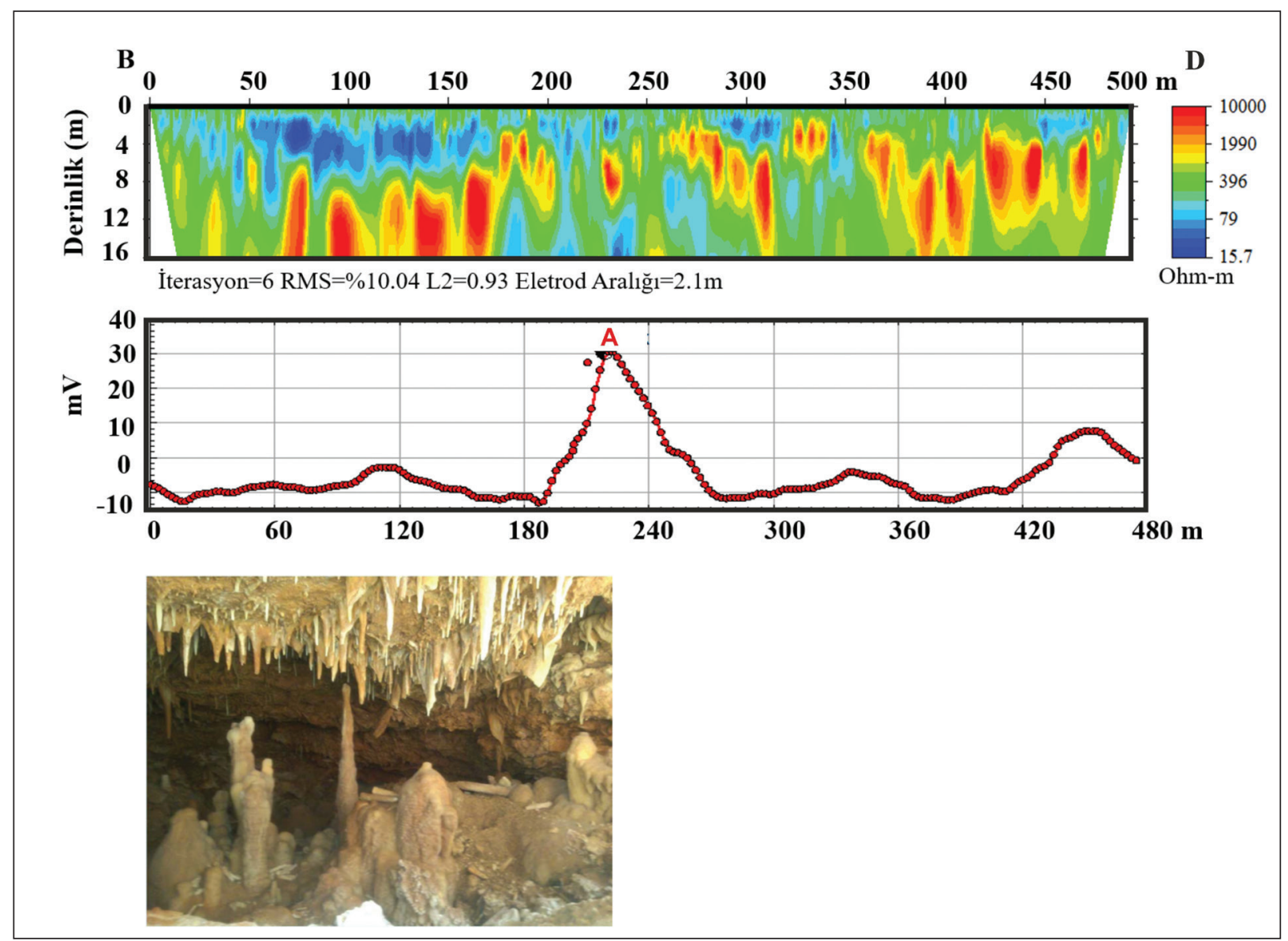

Şekil 11. (a) McNeil yolu üzerindeki jeofizik profile ait özdirenç ve (b) SP kesitleri. (c)'de ise "A" ile etiketlenmiş SP anomalisinin gözlendiği lokasyonda bulunan mağaranın resmi verilmiştir.

Figure 11. Resistivity (a), SP (b) data along the McNeil Drive. (c) shows the picture of the cave discovered beneath the SP anomaly labeled with " $A$ ". 


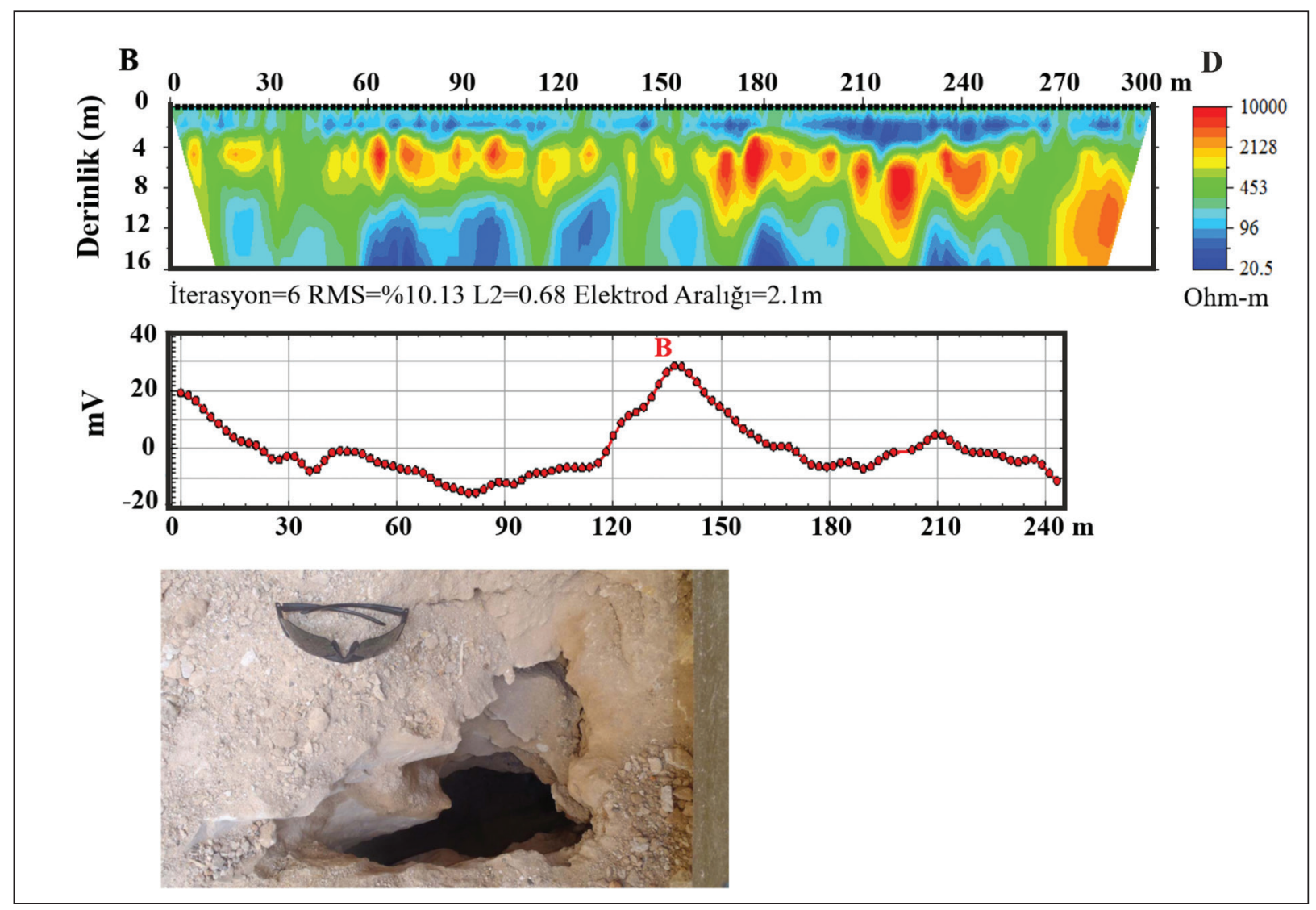

Şekil 12. (a) McNeil yolu üzerindeki jeofizik profile ait özdirenç ve (b) SP kesitleri. (c)'de ise "B" ile etiketlenmiş SP anomalisinin gözlendiği lokasyondaki mağaranın resmi verilmiştir.

Figure 12. (a) Resistivity, (b) SP data along the McNeil Drive. (c) shows the picture of the cave discovered beneath the SP anomaly labeled with " $B$ ".

\section{Araştırma Sahası: McNeil Yolu üzerindeki Weldon Mağarası}

McNeil yolu yakınındaki mağaralardan biri olan Weldon mağarası, içinde nesli tükenmekte olan türleri barındıran bir mağaradır (konum için bkz. Şekil 12). Bu alanda mağaralar, Grainstone Formasyonu ile bu formasyonun altında bulunan Edwards aquiferi'nin Kirschberg üyelerine ait birimlerinden oluşmuştur (Hauwert, 2010). Mağara bir girişle başlar ve birçok yönde ilerlemiş hava-dolu odalardan oluşur.
$\mathrm{Bu}$ bölgede alınan özdirenç ölçüleri, mağara girişinin altındaki alanda düşük ve yüksek özdirenç geçişi gözlenmektedir. Kırmızı renk ile gösterilen yüksek özdirenç değerleri, mağara girişinin batı ve doğu tarafına dalgalı bir geometri gösterir (Şekil 13b).

SP verileri de ayrıca bir mağara sistemini temsil eden M-tipi bir SP anomalisi gösterir. Weldon mağarasının haritası, 2010 yılında Hauwert tarafindan çizilmiştir ve sonuçlar jeofizik verilerle uyum içerisindedir. 


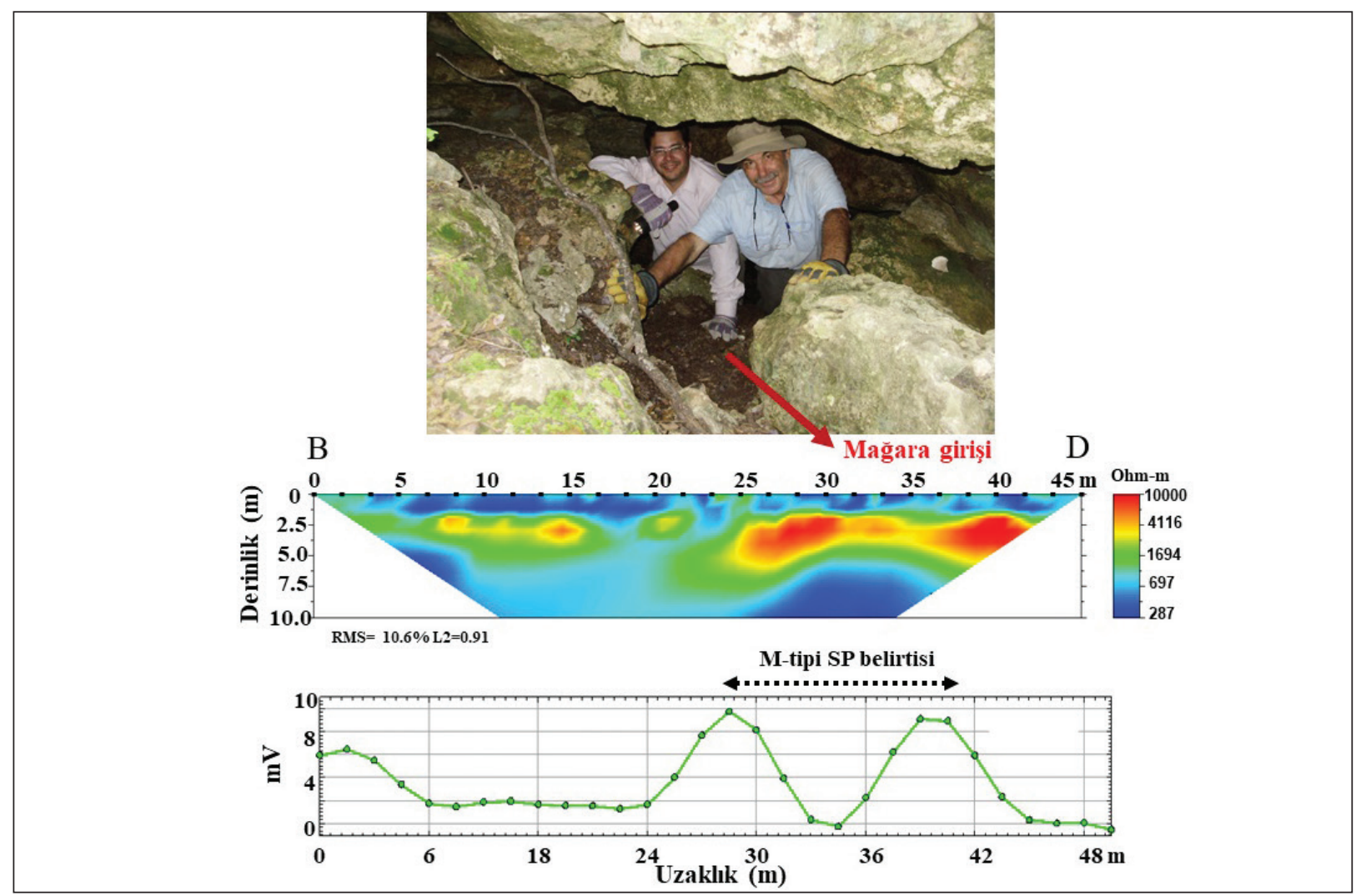

Şekil 13. (a) Weldon mağarası girişini gösteren resim, (b) özdirenç ve (c) SP kesiti.

Figure 13. (a) A picture showing the entrance of Weldon cave, (b) resistivity data, and (c) SP data .

\section{Araştırma Sahası: Austin'deki Çökme Obruğu}

Yakın zamanda güney Austin bölgesinde meydana gelen çökme obruğunun yatay ve düşey yöndeki uzanımını tayin etmek için özdirenç ve SP ölçümleri alınmıştır. Elde edilen sonuçlar (özdirenç ve SP) ile obruğa ait bir fotoğraf Şekil 14 'de verilmiştir.

Özdirenç ölçümleri için seçilen profil, eğimli bir topoğrafyaya sahiptir. $\mathrm{Bu}$ nedenle, EarthImager 2D yazılımı kullanılarak, topografik araştırma sonucundan elde edilen düzeltme değerleri özdirenç ölçüm istasyonlarına atanmıştır. Yükseklik düzeltmesi yapılan özdirenç verileri obruğun olduğu lokasyonda yüksek ve düşük özdirenç geçişi sergiler (Şekil 14a). Bu anomaliler bölgede bir karstik yapının varlığını işaret etmektedir. Doğal potansiyel verisi (SP), obruk yapılarından beklendiği gibi belirgin bir negatif anomali göstermektedir. Yüzeyde görünen obruğun en derin kısmında en düşük SP genliği $(-8 \mathrm{mV})$ gözlenmiştir. SP anomalisi profilin 14 m ile 27 arasında gözlenmektedir ve anomaliye neden olan kaynağın büyük bir olasılıkla yeraltında düşey yönde sızan sudan kaynaklandığı düşünülmektedir. 


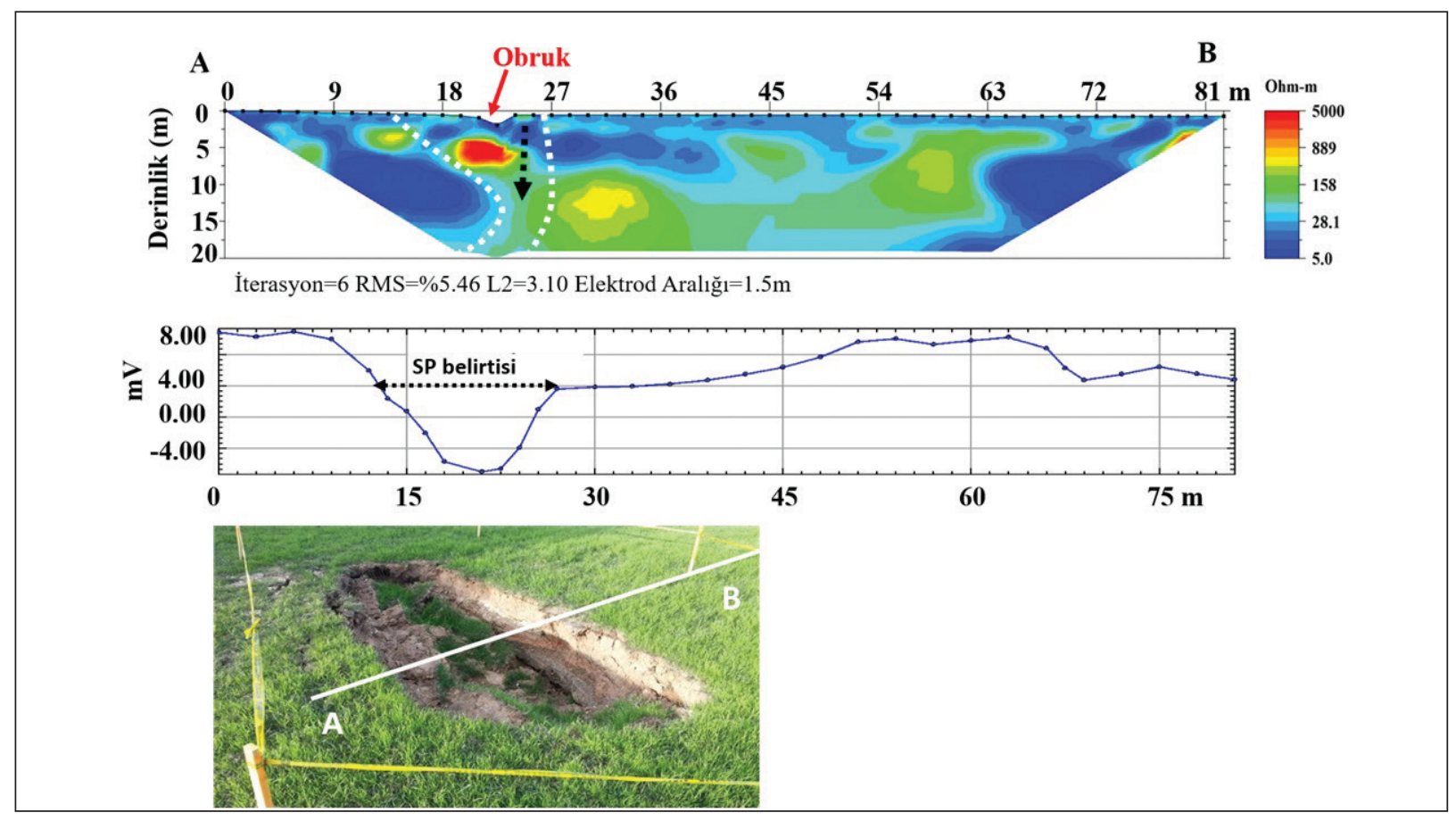

Şekil 14. Obruk üzerinde alınan özdirenç (a) ve SP (b) ölçümlerine ait kesitler. Obruğun lokasyonu özdirenç profili üzerinde verilmektedir. Yüksek ve düşük özdirenç anomalilerinin birleştiği alanda belirgin bir SP anomalisi görülmektedir. Özdirenç kesitinde verilen kesikli siyah ok, obruğun altındaki toprağın kayabileceği doğrultuyu ifade etmektedir. (c) de ise obruğun fotoğrafi ve ölçüm alınan $\mathrm{AB}$ profili gösterilmektedir.

Figure 14. Sections of resistivity (a) and SP (b) measurements taken on the sinkhole. The location of the sinkhole is given on the resistivity profile. A significant SP anomaly is observed in the area where high and low resistivity anomalies meet. The dashed black arrow given in the resistivity section refers to the direction under which the soil below the sinkhole can slip. In (c) the fotography of the sinkhole and the location of the AB profile are shown.

\section{Araştırma Sahası: Flint Sırtı Mağarası}

Travis bölgesinde bulunan Flint S1rtı mağaras1, Austin'deki bilinen en büyük mağara sistemlerinden biridir. Bölgedeki en önemli yeraltısuyu beslenme kaynağı olan bu mağara 28 hektarlık bir drenaj havzasını boşaltmaktadır. Her yı1, Flint Sırtı mağarasından yaklaşık 217 milyon litre su Edwards akiferini beslemektedir (Elliott, 1997).

Austin'deki Lower Colorado Nehir İdaresi'ne ait iletim hattında jeofizik çalışmalar yapıldığı sırada Flint Sırtı Mağarası'nda da elektrik özdirenç ve doğal potansiyel (SP) ölçümleri gerçekleştirilmiştir. Mağara, Kainer Formasyonu'nun Kirschberg ve Dolomitik birimlerinden oluşmaktadır (bkz. Şekil 2). Mağaranın derinlik kesiti ve harita görünümü sırasıyla Şekil 15a ve b'de verilmektedir. Mağara girişindeki obruk yapısını (Şekil 15c) farklı yönlere uzanmış birçok oda izlemektedir (Veni, 2000).

Mağaradaki lokasyonların bir kısmı yeryüzünde referans noktası olarak işaretlenmiştir. $\mathrm{Bu}$ noktalardan biri olan "Formasyon Çukuru", yüzeyin 3 metre altında meydana gelmiştir ve dar bir oda şeklinde gelişmiştir (bkz. Şekil 15a ve b). 
(a)
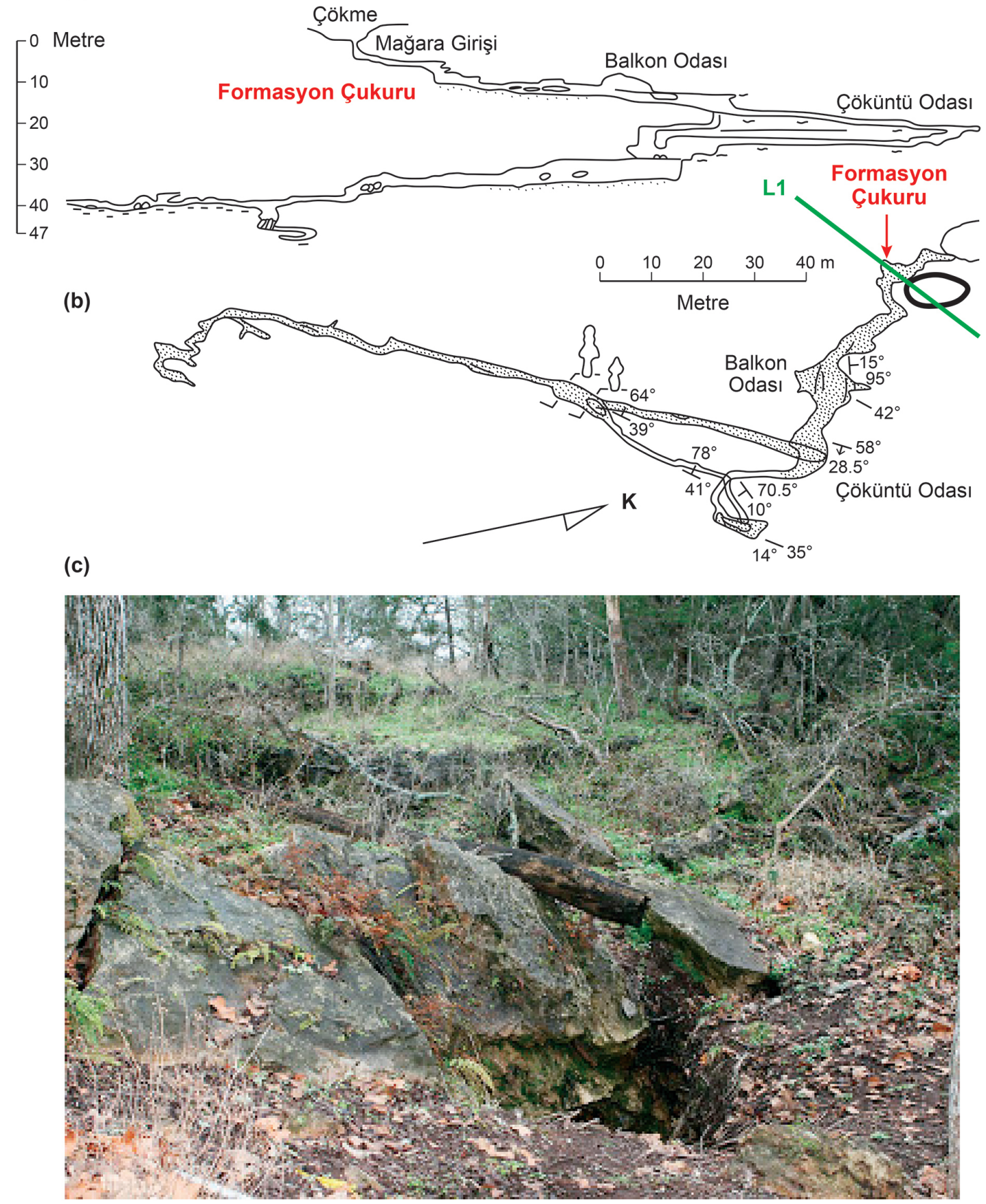

Şekil 15. (a) Flint Sırtı Mağarası'nın derinlik kesiti ve (b) harita görünümü (Jenkins vd., 1999'dan uyarlanmıştır). L1 etiketli yeşil çizgi özdirenç ve doğal potansiyel ölçümlerinin alındığı profili göstermektedir. (c) Flint Sırtı Mağarası'nın girişine ait bir fotoğraf.

Figure 15. (a) Site map showing the depth and (b) map view of Flint Ridge Cave (modified from (Jenkins vd., 1999). Green line with denotation L1 shows the location of the resistivity and SP surveys. (c) Picture of Flint Ridge cave entrance. 


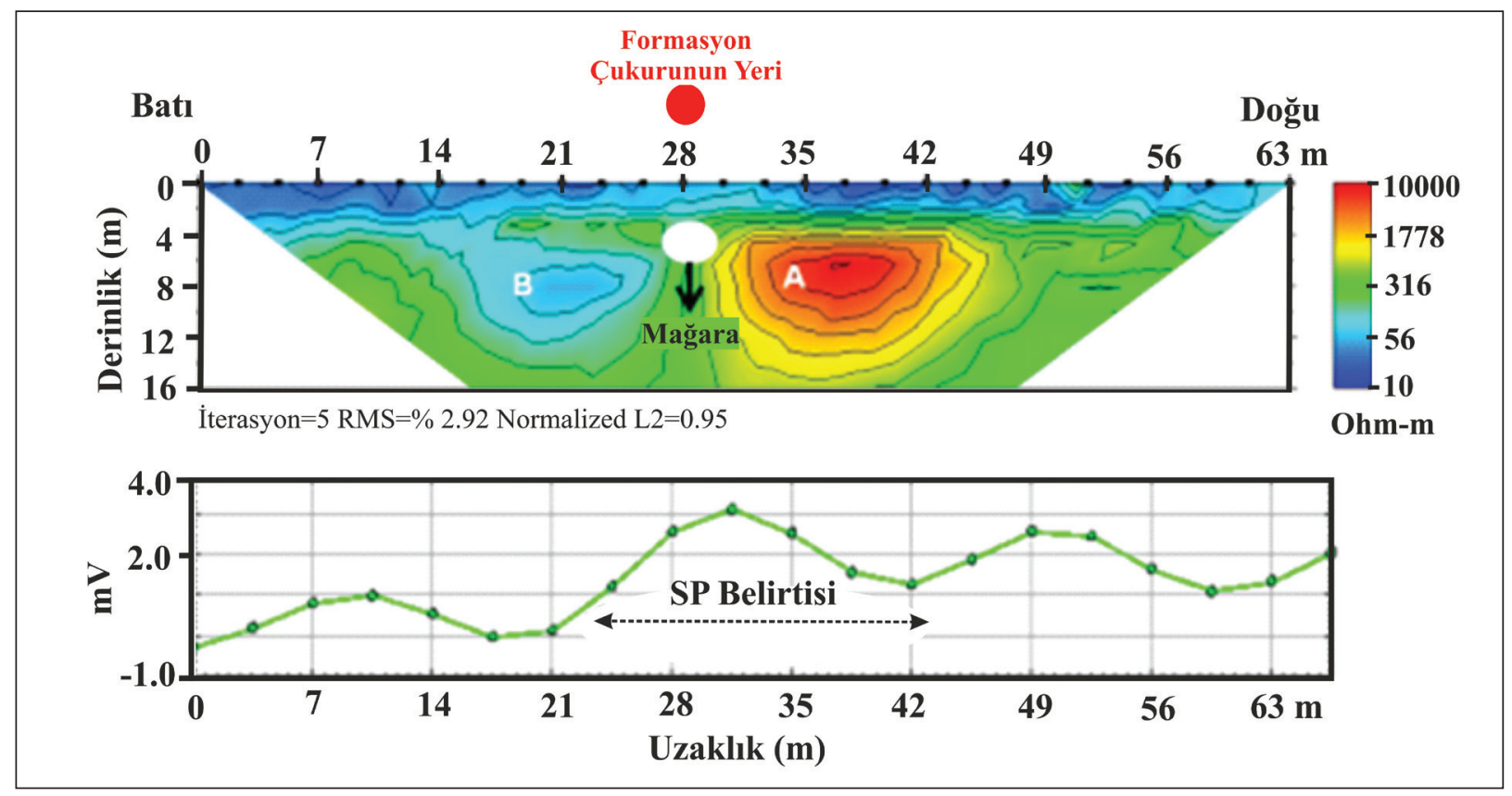

Şekil 16. (a) L1 profili boyunca alınan özdirenç ölçümlerinden elde edilen kesit. Formasyon Çukuru'nun lokasyonu kırmızı, mağaranın lokasyonu ise beyaz dolgulu daire ile temsil edilmiştir. (b) L1 profili boyunca elde edilen SP değerleri. En yüksek SP potansiyel değerinin gözlendiği lokasyon ile mağaranın lokasyonu iyi bir korelasyon göstermektedir.

Figure 16. (a) Resistivity section along the L1 profile. Location of the Formation Pit and the cave are shown with a red-filled and white-filled circles, respectively. (b) SP section along the L1 profile. A high SP anomaly correlates well with the location of the cave.

Şekil 16a'daki özdirenç kesiti incelendiğinde, profil boyunca yüksek özdirenç ve düşük direnç değerlerine sahip lokasyonlar görülmektedir. Referans noktası olarak seçilen Formasyon Çukuru'nun konumu özdirenç kesitinde kırmızı daire, Formasyon Çukuru'nun 3 metre altında yer alan mağaranın lokasyonu ise beyaz renkli daire şeklinde işaretlenmiştir (bkz. Şekil 16a). Mağaranın bulunduğu lokasyondaki özdirenç değerleri orta seviyelerdedir (yaklaşık 300 Ohm.m) ve batısındaki düşük özdirenç değerine sahip zon (50-100 Ohm.m arasında) ile doğusundaki yüksek özdirençli zonun (2000-10000 Ohm.m arasında) kesişim noktasında yer almaktadır. Bu tip bir özdirenç anomalisi bir kırık veya fay zonundan kaynaklanabilir. Burada Flint Sırtı Mağarası'nın bu bölümünün havayla dolu olduğunu ve Formasyon Çukuru'nun olduğu bölgede gözlenen orta seviyeli özdirenç değerlerinin tamamen hava ile dolu boşluklardaki özdirenç değeri kadar yüksek olmadığını belirtmek gerekir. Bunun nedeni ise mağarada bulunan kil ve kum gibi islak sedimentler olabilir. L1 profili boyunca toplanan SP verileri, Şekil 16b'de verilmiştir. En yüksek potansiyel değeri $(3 \mathrm{mV})$ Formasyon Çukuru'nun bulunduğu lokasyon ile uyum göstermektedir.

\section{Araştırma Sahası: Bonnell Dağı Fayı}

Bu araştırma sahasındaki jeofizik çalışmalar Bonell Dağ1 Fay1 boyunca orta Texas'daki Balcones Fay Zonu'nun (BFZ) içersinde kalan 3 profil boyunca yürütülmüsstür. Ancak burada sadece Şekil 17'deki 3 numaralı çalışma sahasına ait sonuçlar tartışılacaktır. Bonnel Dağı Fayı normal bir fay olup yüzlerce metrelik atıma sahiptir. $\mathrm{Bu}$ 
fay, Trinity ve Edwards akiferleri arasındaki sınırı oluşturmaktadır. Yeryüzüne yakın kesimlerde bu fay, kireçtaş1 ve marn-kireçtaşı ara katmanlarından oluşan Üst Glen Rose Formasyonu ile doğu kesimde bulunan çoğunlukla kireçtaşından oluşan Edwards Gurubu kayaçları yan yana getirmektedir (Şekil 17). bir oyuk şeklinde bir karstik yapı neden olduğu düşünülmektedir.

Jeolojik verilerden yol çıkılarak, Bonnell Dağı Fayı'nın lokasyonu elde edilen özdirenç kesiti üzerinde gösterilmiştir. Ancak Bonnell Dağ1 Fayı'nın bulunduğu lokasyonda özdirenç kesitinde

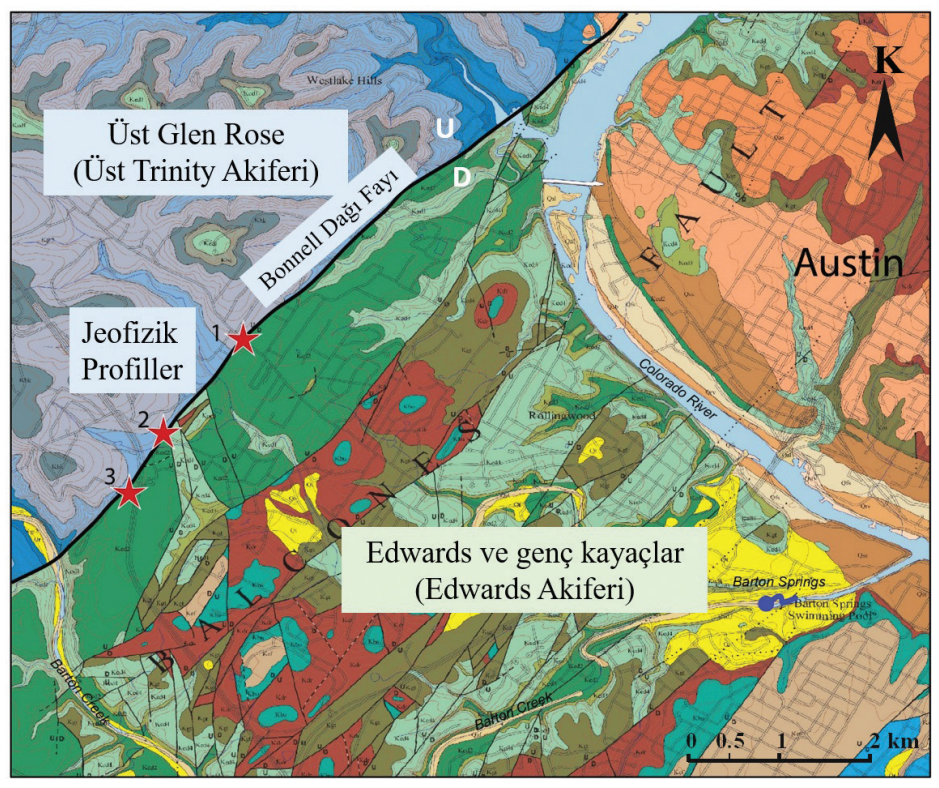

Şekil 17. Bonnell Dağı Fayının jeoloji haritası (Garner vd., 1976) ile jeofizik çalışmaların yapıldığı profiller (kırmızı yıldız). Bu makalede 3. profile ait sonuçlar tartışılmıştır.

Figure 17. Geological map (modified from Garner vd., 1976) showing the Mt. Bonnell Fault and locations of the geophysical transects of \#1, 2 and 3. Only the transect \#3 is discussed in this paper.

Bonnell Dağ fayının Güney Austin'deki 360 Otoyol'u ile kesiştiği bölgede yer alan Height Drive yolu üzerinde elektrik özdirenç, doğal potansiyel ve GPR verisi toplanmıştır (Bkz. Şekil 17, 3 numaralı yıldız). Özdirenç ve doğal potansiyel ölçümleri çim kaplı bir toprak üzerinde, GPR verisi ise özdirenç ve doğal potansiyel ölçümlerinin alındığ 1 profilin yanında asfalt kaplı zemin üzerinde toplanmıştır (Şekil 18). Profil üzerinde 80. ve 95. istasyonlar arasında yüksek ve düşük özdirenç geçişinin olduğu bir anomali gözlenmiştir. Anomaliye neden olan kaynak bilinmemektedir ancak bu anomaliye kil dolu fay benzeri bir anomali görülmemektedir (Şekil 19a). Bu gözlem, Glen Rose biriminin yukarı doğru ötelenmiş kısmındaki özdirenç değerleri ile yüzeye yakın derinliklerde bulunan Edwards akiferi birimlerinin benzer özdirenç değerlerine sahip olduğunu ortaya koymaktadır. SP kesiti ise fayın olduğu lokasyonda yüksek anomali değerleri göstermektedir (Şekil 19b). Ayrıca özdirenç anomalisinin gözlendiği noktada da yüksek bir SP anomalisi gözlenmektedir ancak bu anomali SP fay anomalisinin baskın etkisi nedeniyle çok belirgin değildir. 


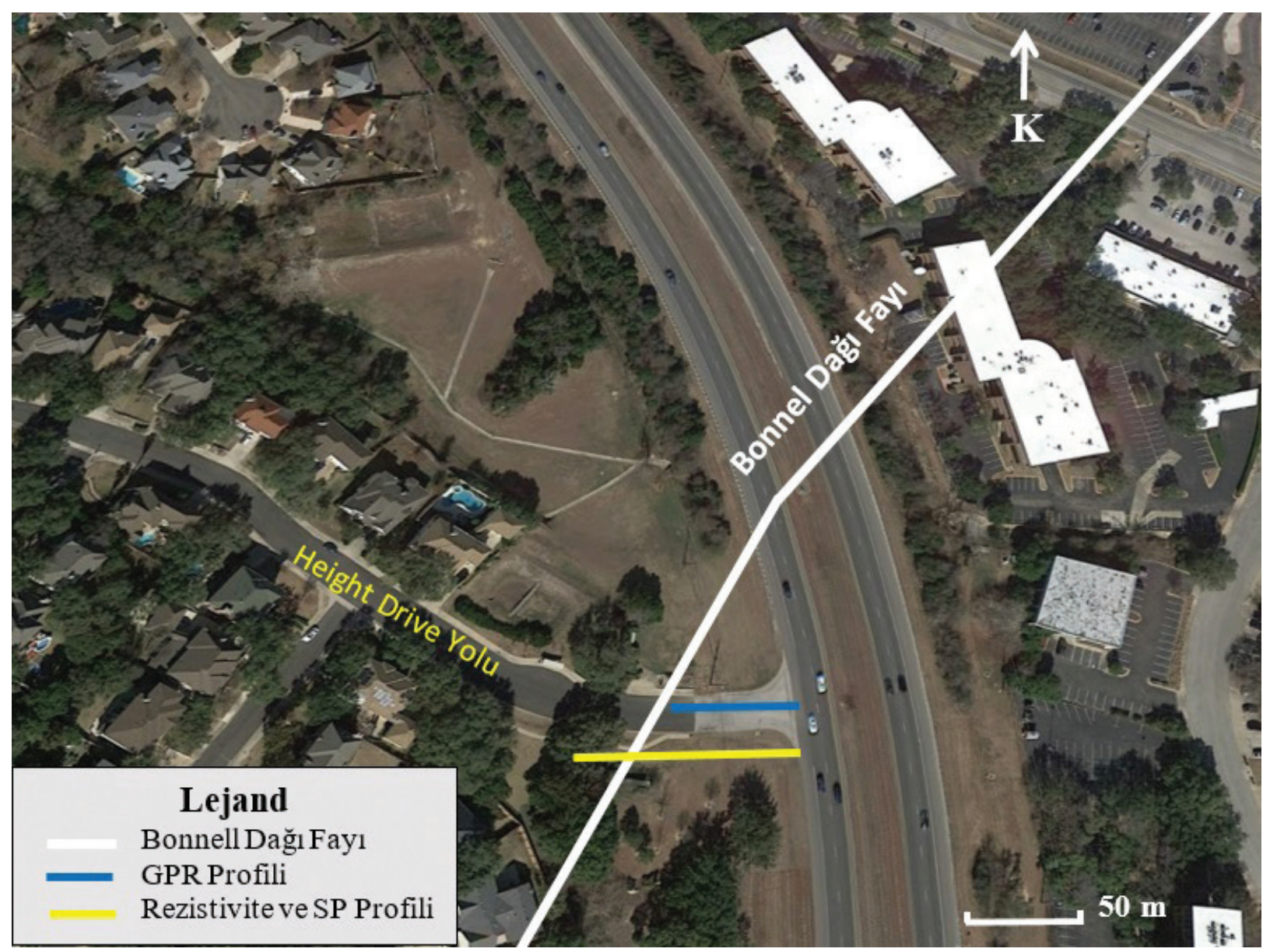

Şekil 18. Height Drive yolu üzerindeki Bonnell Dağı Fayının ve jeofizik ölçümlerin alındı̆̆ı profilleri gösteren harita.

Figure 18. Map showing locations of geophysical profiles and the Mt. Bonnell fault at Height Drive.

GPR verisi incelendiğinde (Şekil 19c) Bonnell Dağı fayı üzerinde belirgin bir genlik kontrast1 görülmektedir. Jeolojik haritalarda verilen fayın lokasyonu, GPR kesitinde gözlenen genlik kontrastı ve SP verisinde gözlenen yüksek anomali değerleri ile uyum göstermektedir. Glen Rose Formasyonu (düşük genlikleri temsil eden mavi, yeşil, sarı ve kahverengi renkler) ile Edwards Akiferi birimleri (yüksek genlikleri temsil eden beyaz ve gri renkler) yan yana bulunmaktadır. Özetle, bu çalışmada yapılmış olan jeofiziksel çalışmalar Glen Rose (Üst Trinity) ve Edward akiferi birimleri arasında kalan bölgede olası karst yapısının varlığını ve Bonnell Dağ1
Fayı'nın lokasyonunu destekler niteliktedir. Şekil 19a' daki özdirenç kesitinde gözlenen mağara benzeri anomali, Earth Resistivity Imager yazılımı kullanılarak modellenmiştir (Şekil 20). Kil- dolu boşluk içeren bir model ve onu çevreleyen 200 Ohm-m direncli bir tabaka için elde edilen özdirenç anomalisi (Şekil 20b), Şekil 19a'da gözlenen anomali ile benzerlik göstermektedir. Ayrıca arazi gözlemleri sırasında boşluk anomalisinin bulunduğu lokasyonun üzerinde yer alan mermer bloğunda (Şekil 21) belirgin bir deformasyon gözlenmiştir. Bu deformasyonun yeryüzüne yakın bir noktada bulunan boşluk sistemindeki çökme etkisiyle oluştuğu düşünülmektedir. 


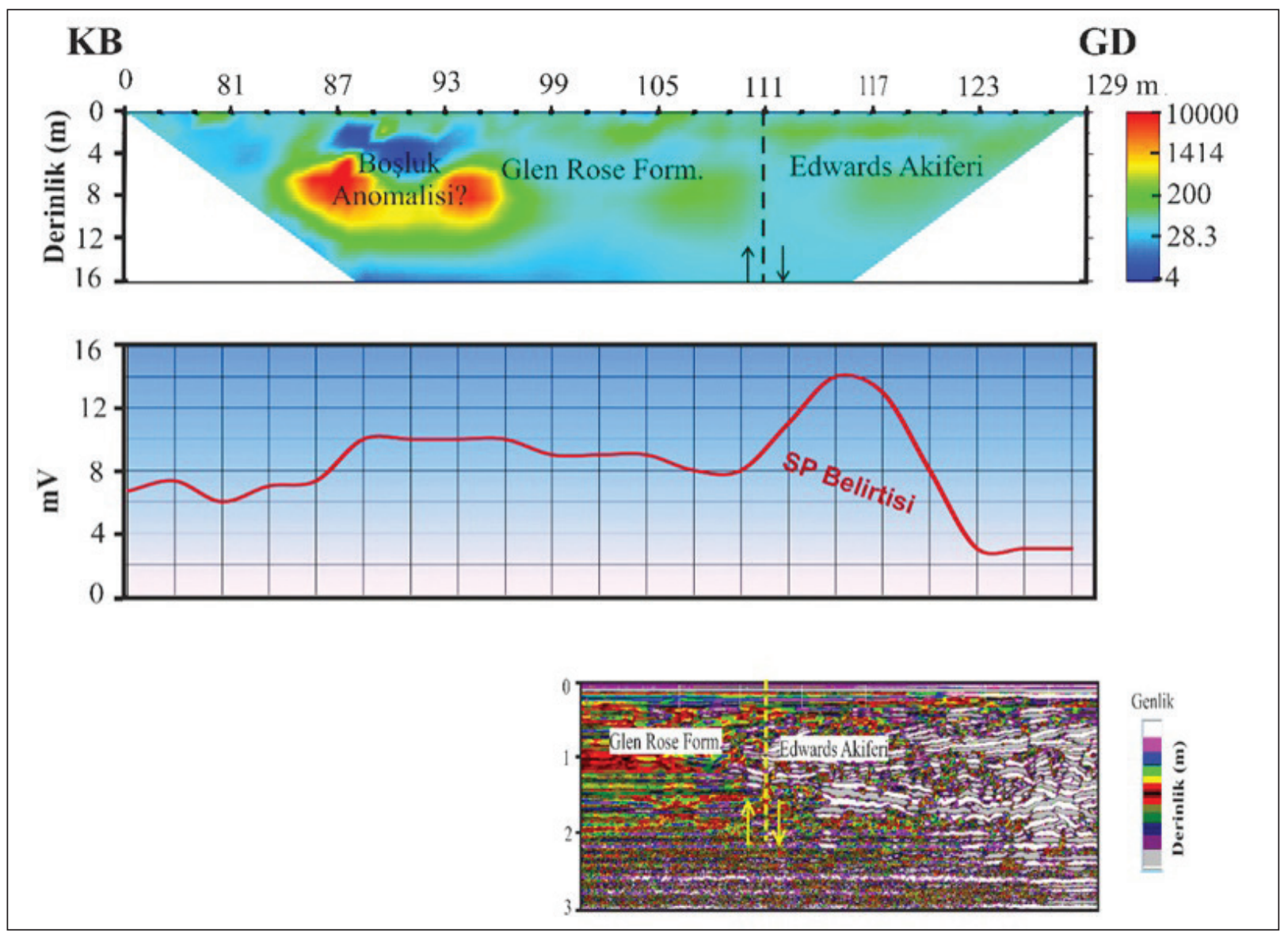

Şekil 19. Bonnell Dağı Fayı boyunca alınan (a) özdirenç, (b) SP ve (c) GPR verisi. GPR kesitindeki yatay ölçek, özdirenç ve SP kesitlerine ait yatay ölçekten farklıdır.

Figure 19. Resistivity (a), SP (b) and (c) GPR data across the Mt. Bonnell fault. Note that the horizontal scale of the $G P R$ data is different than both the resistivity and SP profiles. 


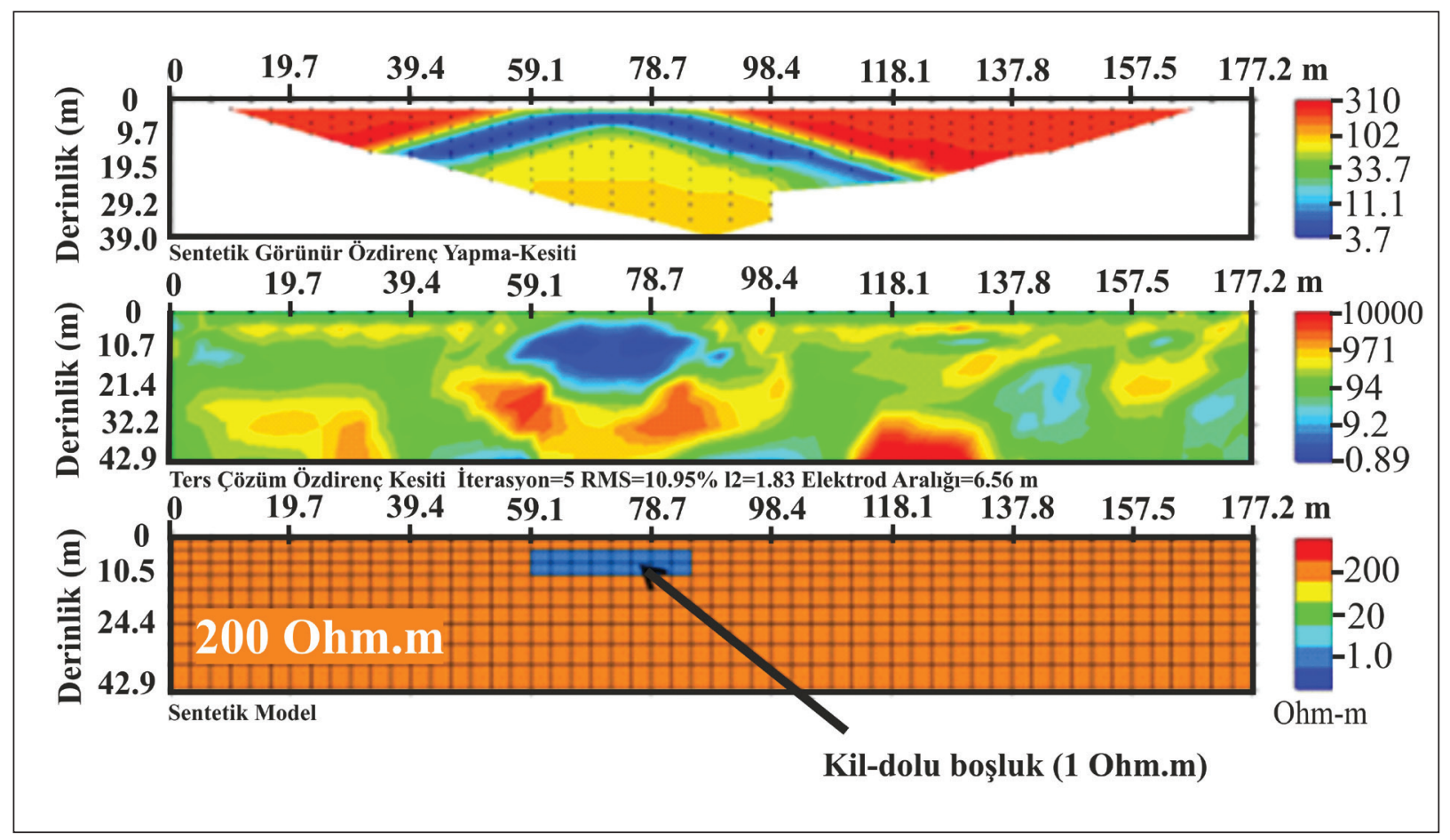

Şekil 20. (a) Sentetik görünür özdirenç yapma-kesiti, (b) ters çözüm ile elde edilen özdirenç kesiti ve (c) kil- dolu boşluğu temsil eden sentetik model.

Figure 20. (a) Synthetic apparent resistivity pseudosection (b) inverted resistivity section and (c) a clay-filled void model.

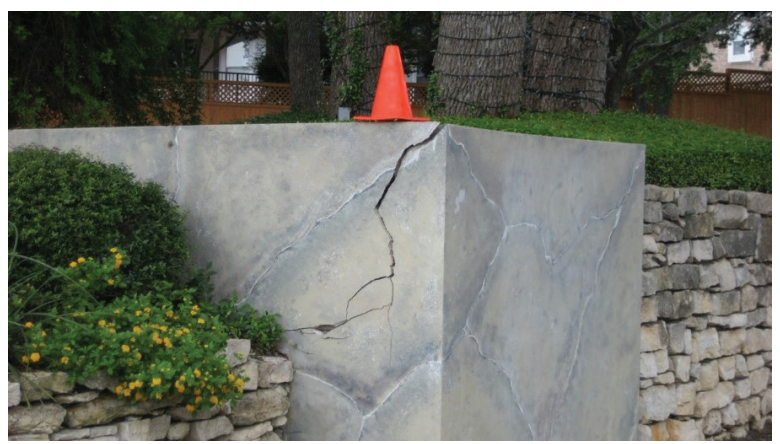

Şekil 21. Height Drive bölgesinin girişinde ve boşluk yapısının üzerinde yer alan mermer bloğunda gözlenen deformasyon.

Figure 21. Marble displays at the entrance of the Height Drive neighborhood showing significant deformation where the cave anomaly is detected.

\section{SONUÇLAR VE TARTIŞMA}

Bu çalışmada elde edilen sonuçlardan görüleceği üzere, 2B özdirenç ölçümleri ile yeraltındaki karstik yapıların lokasyonlarının saptanması her zaman mümkün olmamaktadır ancak bu yöntem ile yüzeye yakın jeolojik birimler ve yapılar hakkında önemli bilgiler sağlanabilmektedir. Bununla birlikte, 2B ve 3B özdirenç ölçümlerinin birlikte değerlendirilmesi bu yapıların daha doğru bir şekilde saptanması sağlamaktadır. Öte yandan, SP ölçümleri karstik yapıların konumunu belirlemede oldukça başarılıdır. $\mathrm{Bu}$ nedenle, yorumlamadaki belirsizliği azaltmak için özdirenç yöntemi ile birlikte SP yöntemi de kullanılmalıdır.

Edwards ve Trinity akiferlerinin olduğu bölgede yer alan gömülü obrukların, boşlukların ve boru hatlarının bulunmasında yüzey jeofizik yöntemleri son 15 yıldır kapsamlı ve başarılı bir 
şekilde kullanılmaktadır. Bölgede yapılan diğer çalışmalar fayların ve kırıkların tanımlanması ve karakterizasyonu, hidrostratigrafi ve anakaya topografyasının araştırılmasını içerir. $\mathrm{Bu}$ başarının anahtarlarından biri, araştırmalarda iki veya daha çok jeofizik yöntemin bütünleşik kullanımından elde edilen sonuçların kapsamlı jeolojik bilgiler ile birlikte yorumlanmasıdır. Her ne kadar farklı karstik bölgelerde, farklı yüzey jeofizik yöntemlerini daha iyi sonuç verebilecek olsa da bu çalışmanın sonuçları Orta Texas'taki Edwards ve Trinity akiferlerinin bulunduğu bölgede karstik yapıların saptanmasında özdirenç ve doğal potansiyel (SP) yöntemlerinin birincil jeofizik yöntemler olarak kullanılabileceğini göstermektedir.

Hali hazırda, karstik yapıların araştırılmasında kullanılmakta olan jeofizik yöntemler özdirenç (2B ve 3B), doğal potansiyel (SP), yer radarı (GPR), gravimetri, manyetik, elektromanyetik ve sismik yöntemlerdir (kırılma, yansıma ve MASW). Bu jeofizik yöntemler kullanarak yeni oluşmakta olan obruklar, ana kaya oyukları, kaya tepeleri ve diğer karst yapıları saptanabilmektedir. Ancak jeolojik faktörlere ve yeraltındaki yapının büyüklüğüne, şekline ve yönelimine bağlı olarak yöntemlerin nüfuz derinliği ve çözünürlük sınırları değişmektedir. Buna ek olarak, gravite ve sismik gibi bazı yöntemler daha uzun ölçüm süreleri nedeniyle maliyet açısından kısıtlayıcı olabilmektedirler.

\section{KATKI BELİRTME}

$\mathrm{Bu}$ çalışmanın makale formatına dönüşmesinde yardımcı olan Öğr. Gör. Karolin Fırtana-Elcömert ve Yük. Müh. N. Gözde Okut-Toksoy'a teşekkür ederim. Makaleye hakem olarak onemli katkılar sunan Yunus Levent Ekinci ve Cahit Çağlar Yalçıner'e teşekkür ederim.

\section{EXTENDED SUMMARY}

Geophysical methods are powerful tools to explore the subsurface. The geophysical information can be used to locate caves and sinkholes in the subsurface, quantify hazard estimates for structures being planned over karstic landscapes, explore groundwater resources, and characterize geologic structure. Currently, several geophysical methods exist to locate karstic features. These geophysical methods are resistivity (2D and $3 D)$, self-potential (SP), ground penetrating radar (GPR), gravimetry, magnetics, electromagnetics, and seismic [refraction, reflection and multiple analysis of seismic waves (MASW)] Detecting incipient sinkholes, bedrock cavities, rock pinnacles, and other karst-related features using these geophysical methods has been proven over the years. But each method has limitations in depth and resolution accuracy based on geological factors and void size, shape, and orientation. In addition, some methods, such as gravity, and seismic, take longer and they may be cost-inhibitive.

The motivation of this paper is to show how integrated geophysical methods could provide significant information on locating karstic features and fault characterization in the Edwards aquifer, Central Texas, USA. The karstic Edwards aquifer in the Balcones Fault Zone (BFZ) in southcentral Texas is a 90-210-m thick a porous, honey-combed, water-bearing formation. The structural framework of the Edwards Aquifer is controlled by the BFZ, an echelon array of normal faults that has extended and dropped the aquifer and associated strata from northwest to the southeast across the three segments (Small vd., 1996; Ferrill and Morris., 2005). The BFZ includes the karstic Edwards and Trinity aquifers, which are primary sources of water for southcentral Texas communities, including the city of San Antonio. Six case studies presented here demonstrate that geophysical methods can be used effectively to locate faults, karstic features 
(caves and sinkholes), map stratigraphy and geologic structure of the Edwards Aquifer, which is bounded by the BFZ.

The first survey area was the Barton Spring Pool Conduit located on the grounds of Zilker Park in Austin, Texas. The pool exists within the channel of Barton Creek and utilizes water from Main Barton Spring, the fourth largest spring in Texas at Main Barton Springs. The Main Barton Springs and several outlets along a cave, several fissures, and gravel-filled solution cavities on the floor of the pool west of the fault discharge into the Barton Springs pool (Hauwert, 2009). The surface geology of the Main Barton Springs area includes Edwards Aquifer units (regional dense and leached collapsed members) and the Georgetown Formation (Hauwert, 2009). Multiple geophysical surveys were conducted in the vicinity of the Barton Spring Pool in Austin, Texas (Saribudak vd., 2013; Saribudak and Hauwert, 2017). Electrical resistivity (2D and 3D), self-potential, induced polarization (IP) and tomographic seismic refraction surveys were conducted on an east-west transect along the southern fenceboundary of the swimming pool at Zilker Park (see site map of Figure 6 for location). The SP data on the south bank indicate a low SP anomaly (A1) at station $60 \mathrm{~m}$. This anomaly corresponds to where the Barton Springs Fault crosses the pool (Fig. 7). The source for this anomaly could be a cave. The SP data indicates a significant high SP anomaly (A2) between stations 75 and $120 \mathrm{~m}$. The location of this anomaly is closer where the Main Barton Springs discharges into the pool. Thus the source for this SP anomaly could be related to the discharging groundwater into the pool. The resistivity data (Figure 8a) indicates a significant low resistivity anomaly (blue in color) at a depth of about $10 \mathrm{~m}$ ). The anomaly has a width of $10 \mathrm{~m}$ and appears to dip to the east. The low resistivity anomaly is interpreted to be caused by combination of water and/or presence of clay associated with a karst conduit. The IP data illustrates a high IP anomaly (red in color) at the same location as the low resistivity anomaly (Figure $8 b$ ). The source of the IP anomaly could be due to clay formations and/or mineralization such as sulphide particles. The seismic refraction data not only define the geological units (Edwards aquifer units and Georgetown Formation), but also displays a faultlike anomaly (Figure 8c). 3-D resistivity block diagram was constructed using the resistivity profile L1 and other previously published four east-west resistivity profiles and is shown in Figure 9a. A SP profile, which was surveyed along profile $L 1$ is also shown in Figure 9b. 3-D diagram indicates a well-defined low resistivity zone where the high SP anomaly is located. In summary, results of all geophysical data suggests a presence of a conduit anomaly and a newly discovered fault near the south gate entrance to the swimming pool, which is approximately aligned where Main Barton Springs discharges to the Barton Springs Swimming pool.

The second survey area was the McNeil Caves. Several karst features were identified by the City of Austin in the vicinity of the Recharge Zone. These features include a sinkhole/cave opening located behind McNeil High School; the McNeil Bat Cave, located on the east side of the high school; and two other caves (Weldon Cave, No Rent Cave) located west of the high school. Multiple geophysical surveys (electrical resistivity, SP, GPR, magnetic, and ground conductivity) were performed across the site (Saribudak, 2015). In this paper, however, only resistivity and SP results are discussed for the MHTM project and Weldon Cave (see Figure 10 for location). The resistivity data indicate a high resistive layer undulating under a low resistive layer along the profile. The SP data (Figure 11b) displays a significant high anomaly, shown with a red font letter $A$, with a horizontal coverage of 60 meter and a magnitude of $50 \mathrm{mV}$. The SP data (Figure 12b) clearly displays a major anomaly between the stations $121 \mathrm{~m}$ and $168 \mathrm{~m}$, and is denoted with the letter $B$. The maximum magnitude 
of this SP anomaly is about $40 \mathrm{mV}$ from the east side of the study area.

The third geophysical survey was conducted at the Weldon Cave located on the McNeil Drive. The cave starts with an entrance and trends in multiple directions with several air-filled rooms. The resistivity data indicates a combination of low and high resistivity values beneath the cave entrance. High resistivity values, red in color, show an undulating geometry to the west and east side of the entrance of the cave (Figure 13b). The SP data also show a M-type SP anomaly indicating a cave system.

The fourth survey area was Sinkhole Collapse in Austin. Resistivity and SP surveys along across a sinkhole that recently occurred in the south Austin area was performed. The resistivity data was corrected for topography and indicates a combination of high and low resistivity anomalies beneath the sinkhole area (Figure 14a). These anomalies appear to be karstic in origin. The selfpotential data (SP) shows a significant negative anomaly, as expected from sinkholes.

The fifth survey area was the Flint Ridge Cave. It is one of the largest known cave systems in Travis County, Austin and also one of the most important recharge features in the county. Resistivity and SP surveys were conducted at Flint Ridge Cave. Resistivity data show high resistivity and low resistivity anomalies along the profile. The cave location is indicated by medium resistivity values (green in color) and appears to be intersected by low resistivity (blue in color) in the west and high resistivity values (red in color) in the east (Figure 16a). This type of resistivity anomaly could be caused by a fracture or fault. The SP data collected along the profile L1 is given in Figure 16b. The highest SP value of $3 \mathrm{mV}$ correlates well with the location of the Formation Pit and the fracture-like resistivity anomaly across the profile.

The last geophysical surveys were conducted at three locations across the Mount Bonnell fault in the BFZ of central Texas, however, only one transect (\#3) is discussed in this paper (Figure 17). The Mount Bonnell fault is a normal fault with hundreds of meters of throw. It forms the primary boundary between the Trinity and Edwards aquifers. Electrical resistivity, SP and GPR data were collected at the Height Drive transect where the Mount Bonnell fault crosses Highway 360 in South Austin. Resistivity and SP surveys were conducted on a grassy ground whereas the GPR survey was conducted on the asphalt next to the resistivity and SP transects (Figure 18). The resistivity data indicate a significant anomaly consisting of high-and-low resistivity between stations 80 and $95 \mathrm{~m}$. The source for this anomaly is not known, but could be a karst feature such as a clay-filled cave (Figure 19a). The SP data show a significant high anomaly at the known fault location (Figure 19b). The GPR data (Figure 19c) show a significant amplitude contrast across the Mt. Bonnell fault. The fault location defined by the GPR data correlates well with the SP data, and geologic mapping of the fault. The Glen Rose Formation (low amplitudes indicated by blue, green, yellow, and brown colors is juxtaposed with Edwards Aquifer units (high amplitudes of white and gray colors). In summary, geophysical results corroborated the suspected karstic feature in the Glen Rose (Upper Trinity) and Edwards aquifer units and the mapped location of the Mount Bonnell fault. We observed significant deformation over the marble wall displays, which were approximately located where the cave anomaly (resistivity) was located (Figure 20). This is probably due to the settling effect of the cave system in the near-surface.

As a result, it appears that primary geophysical methods for detecting karstic features have been the combination of resistivity imaging and the SP methods in central Texas, although different karstic regions might respond better to disparate surface geophysical methods than the Edwards/Trinity aquifers. 


\section{ORCID}

Mustafa Sarıbudak (D http://orcid.org/0000-0001-5351-5444

\section{DEĞİNILEN BELGELER}

Balkaya, Ç., Göktürkler, G., Erhan, Z., Ekinci, Y. L., 2012. Exploration for a cave by magnetic and electrical resistivity surveys: Ayvacik Sinkhole example, Bozdağ İzmir (Western Turkey). Geophysics, 77 (3), 135-146.

Blome, C.D., Smith, B.D., Smith, D.V., Faith, J R., Hunt, A.G., Moore, D.W. , Miggins, D.P., Ozuna, G.B. and Landis, G.P., 2008. Multidisciplinary Studies of the Edwards Aquifer and Adjacent Trinity Aquifer of South-Central Texas, Search and Discovery Article \#80018. Adapted from oral presentation at AAPG Annual Convention, San Antonio, TX, April 20-23, 2008 (http://pubs.usgs. gov/fs/2006/3145).

Chen, J. and Zelt, C. A., 2016. Application of Frequency-dependent Traveltime Tomography and Full Waveform Inversion to Realistic Nearsurface Seismic Refraction Data. Journal of Environmental and Engineering Geophysics, 21:1-12.

Clark, A.K., Golab, J.A. and Morris, R.R., 2016. Geologic Framework and Hydrostratigraphy of the Edwards and Trinity Aquifers within Northern Bexar and Comal Counties, Texas. USGS Scientific Investigations Map 3366.

Connor, C.B. and Sandberg, S.K., 2001. Application of Integrated Geophysical Techniques to Characterize the Edwards Aquifer, Texas, STGS Bulletin, March issue, p. 11-25.

Elliott, W. R., 1997. The caves of the Balcones Canyonlands Conservation Plan,Travis County, Texas, Unpublished report to Travis County, 156 p.

EarthImager 2D Manual, 2002-2014. Resistivity and IP Inversion Software, Version 2.4.2., by Advanced Geosciences, Inc.

Ferrill, D. A., Morris, A. P. and Waiting, D. J., 2005. Structure of the Balcones Fault System and Architecture of the Edwards and Trinity Aquifers, South-Central, Texas. A field trip guide for the South-Central Geological Society of America Meeting.
Ferrill, D.A. and Morris, A.P., 2008. Fault zone deformation controlled by carbonate mechanical stratigraphy, Balcones Fault System, Texas, AAPG Bulletin, 92, 359-380.

Fitterman, D.V. and Stewart, M.T., 1986. Transient electromagnetic sounding for groundwater, Geophysics, v. 51, p. 995-1005.

Freeland, R. S., 2015. Imaging the Lateral Roots of the Orange Tree using Three-dimensional GPR. Journal of Environmental and Engineering Geophysics, 20:235-244.

Freeland, R. S., Allred, B. J., Martinez, L. R., Gamble, D. L., Jones, B. R. and McCoy, E. L., 2016. Performance of Hybrid and Single-frequency Impulse GPR Antennas on USGA Sporting Greens. Journal of Environmental and Engineering Geophysics, 21:57-65.

Garner, L. E., Young, K. P., Rodda, P. U., Dawe, G. L. and Rogers, M. A., 1974. Geologic map of the Austin area, Texas, in Garner: an aid to urban planning, The University of Texas at Austin,Bureau of Economic Geology, scale 1:65,500.

Gary, M.O., Rucker, D.F., Smith, B.D., Smith, D.V. and Befus, K., 2013. Geophysical investigations of Edwards-Trinity Aquifer System at Multiple Scales: Interpreting Airborne and Direct-Current Resistivity in Karst, $13^{\text {th }}$ Sinkhole Conference, NCKRI Symposium, 2,195-206.

Hauwert, N. M., 2009. Groundwater flow and recharge within the Barton Springs Segment of the Edwards Aquifer, Southern Travis and northern Hays Counties, Texas. A Ph.D. Dissertation; The University of Texas at Austin.

Hauwert, N. M., 2010. Hydrogeologic Study of Fossil Garden, No Rent, Weldon, and McNeil Bat Caves. City of Austin short report SR-11-21.81 p.

Lachhab, A., Booterbaugh, A. and Beren, M., 2015. Bathymetry and Sediment Accumulation of Walker Lake, PA Using Two GPR Antennas in a New Integrated Method. Journal of Environmental and Engineering Geophysics, 20:245-255.

Lange, A. L., 1999. Geophysical studies at Kartchner Caverns State Park, Arizona, Journal of Cave and Karst Studies, 61:68-72.

Lange, A. L. and Kilty, K. T., 1991. Natural potential responses of karst systems at the ground 
surface. Proceedings of the third Conference on Geohydrology, Ecology and Monitoring and Management of Ground water in karst terranes: National Groundwater Association, 179-196.

Musgrove, M. and Banner, J. L., 2004. Controls on the spatial and temporal variability of vadose dripwater geochemistry: Edwards Aquifer, central Texas, Geochimica et Cosmochimica Acta, 68(5):1007-1020.

Parasnis, D.S., 1996. Principles of Applied Geophysics, Springer, $5^{\text {th }}$ Edition.

Revil, A. and Jardani., A., 2013. The Self-Potential Method:Theory and Applications in Environmental Geosciences, Cambridge University Press.

Rose, P. R., 1972. Edwards group, surface and subsurface, Central Texas; Report of Investigations 74, Bureau of Economic Geology: Austin, Texas.

Rucker, D. F. and Ferré, T. P. A., 2004. Automated Water Content Reconstruction of Zero-Offset Borehole Ground Penetrating Radar Data Using Simulated Annealing.Journal of Hydrology, 309 (1-4):1-16.

Rucker, D. F. and Glaser, D. R., 2015. Standard, Random and Optimum Array Conversions from Two-pole Resistance Data. Journal of Environmental and Engineering Geophysics, 20(3):207-217.

Saribudak, M., 2011. Urban geophysics: Geophysical signature of Mt. Bonnell Fault and its karstic features in Austin, Texas, Houston Geological Society Bulletin, October issue, p.49-54.

Saribudak, M., Hawkins, A. and Stoker, K., 2012a. Geophysical signature of Haby Crossing Fault and its implication on the Edwards Recharge Zone, Medina County, Texas: Houston Geophysical Society, 2:9-14.

Saribudak, M., Hunt, S. and Smith, B., 2012b. Resistivity imaging and natural potential applications to the Antioch Fault Zone in the Onion Creek / Barton Springs segment of the Edwards Aquifer, Buda, Texas: Gulf Coast Association of Geological Societies Transactions, 62:411-421.

Saribudak, M., Hauwert, N. and Hawkins, A., 2013. Geophysical signatures of Barton Springs (Parthenia, Zenobia and Eliza) of the Edwards Aquifer, Austin, Texas, Sinkhole Conference 14 proceedings, Carbonite and Evaporites, Springer, ISSN 0891-2556.
Saribudak, M., 2016. Geophysical mapping of Mount Bonnell fault of Balcones Fault zone and its implications on Trinity-Edwards Aquifer interconnection, central Texas, USA, The Leading Edge, p. 936-941.

Saribudak, M. and Hauwert, N.W., 2017. Integrated geophysical investigations of Main Barton Springs, Austin, Texas, USA, Journal of Applied Geophysics, 138, 114-126.

Shah, S.D., Smith, B.D., Clark, A.K. and Payne, J.D., 2008. An Integrated Hydrogeologic and Geophysical Investigation to Characterize the Hydrostratigraphy of the Edwards Aquifer in an Area of Northeastern Bexar County, Texas, USGS Scientific Investigations Report, 2008-5181.

Small, T. A., Hanson, J. A. and Hauwert, N. M., 1996. Geologic framework and hydrogeologic characteristics of the Edwards Aquifer outcrop (Barton Springs Segment), northeastern Hays and southwestern Travis Counties, Texas: U.S. Geological Survey Water Resources Investigations 96-4306, 15 p. Prepared in cooperation with the BS/EACD and TWDB.

Smith, B. D., Cain, M.J., Clark, A.K., Moore, D.W., Faith J.R., and Hill. P.L., 2005. Helicopter electromagnetic and magnetic survey data and maps, northern Bexar County: U.S. Geological Survey Open-file Report 2005-1158.

Uçar, F. ve Aktürk Ö., 2015. İki Boyutlu Elektrik Özdirenç Görüntüleme Yöntemi Kullanılarak Karstik Boşlukların Belirlenmesi, 68. Türkiye Jeoloji Kurultayı, Ankara, Türkiye, 6-10 Nisan 2015, 222-223.

Veni, G., 2000. Hydrogeologic assessment of Flint Ridge Cave, Travis County, Texas. Report for the City of Austin, George Veni and Associates, San Antonio, Texas, $56 \mathrm{p}$.

Vichabian, Y. and Morgan, F. D., 2002. Self potentials in cave detection: The Leading Edge, 23, 866-871.

Wong, C, J.B. Kromann, B. Hunt, B. Smith and Banner, J., 2014. Investigating groundwater flow between Edwards and Trinity Aquifers in central Texas. Groundwater, 52, 624-639. 